\title{
Response of oxide nanoparticles in an oxide dispersion strengthened steel to dynamic plastic deformation
}

Zhang, Zhenbo; Pantleon, Wolfgang

\section{Published in:}

Acta Materialia

Link to article, DOI:

10.1016/j.actamat.2018.02.042

Publication date:

2018

Document Version

Peer reviewed version

Link back to DTU Orbit

Citation (APA):

Zhang, Z., \& Pantleon, W. (2018). Response of oxide nanoparticles in an oxide dispersion strengthened steel to dynamic plastic deformation. Acta Materialia, 149, 235-247. https://doi.org/10.1016/j.actamat.2018.02.042

\section{General rights}

Copyright and moral rights for the publications made accessible in the public portal are retained by the authors and/or other copyright owners and it is a condition of accessing publications that users recognise and abide by the legal requirements associated with these rights.

- Users may download and print one copy of any publication from the public portal for the purpose of private study or research.

- You may not further distribute the material or use it for any profit-making activity or commercial gain

- You may freely distribute the URL identifying the publication in the public portal 


\section{Accepted Manuscript}

Response of oxide nanoparticles in an oxide dispersion strengthened steel to dynamic plastic deformation

Zhenbo Zhang, Wolfgang Pantleon

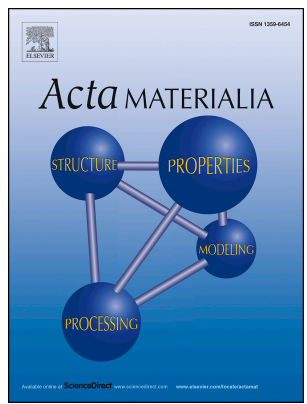

PII:

S1359-6454(18)30150-2

DOI:

10.1016/j.actamat.2018.02.042

Reference: $\quad$ AM 14397

To appear in: Acta Materialia

Received Date: 21 November 2017

Revised Date: 15 February 2018

Accepted Date: 20 February 2018

Please cite this article as: Z. Zhang, W. Pantleon, Response of oxide nanoparticles in an oxide dispersion strengthened steel to dynamic plastic deformation, Acta Materialia (2018), doi: 10.1016/ j.actamat.2018.02.042.

This is a PDF file of an unedited manuscript that has been accepted for publication. As a service to our customers we are providing this early version of the manuscript. The manuscript will undergo copyediting, typesetting, and review of the resulting proof before it is published in its final form. Please note that during the production process errors may be discovered which could affect the content, and all legal disclaimers that apply to the journal pertain. 
(a)

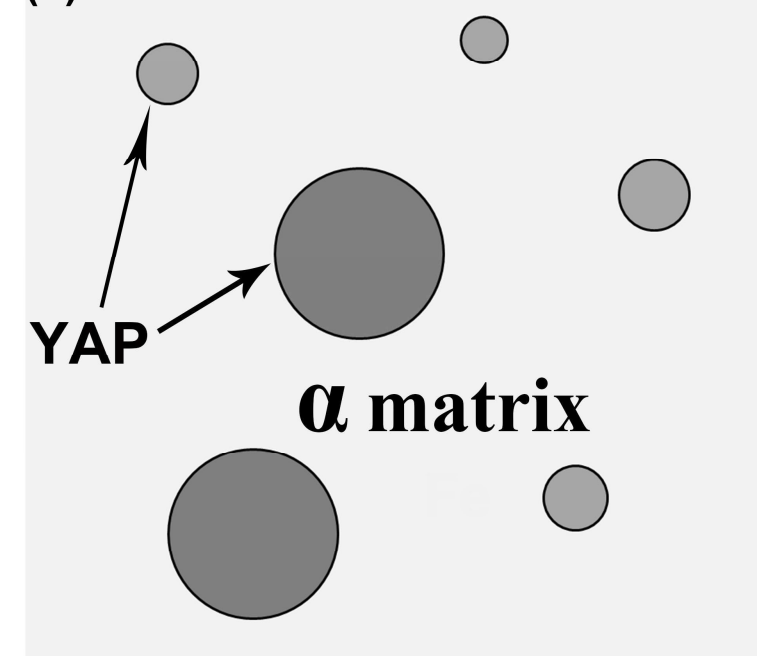

(d)

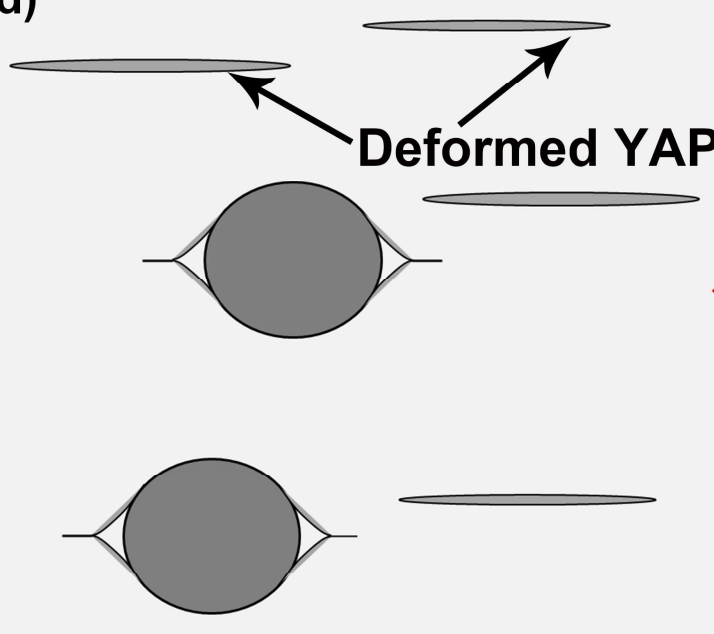

(b)

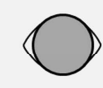

0

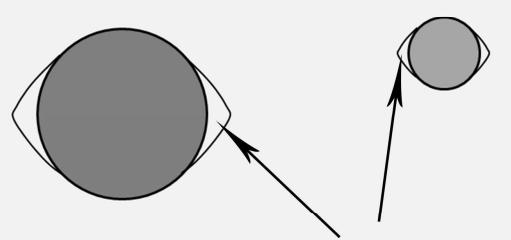

Void
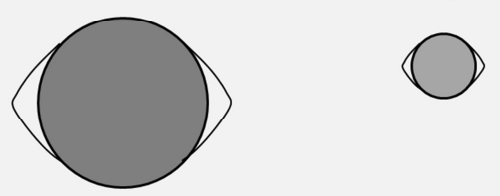

(c)
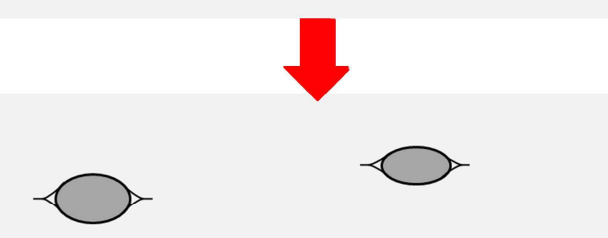

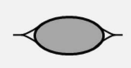

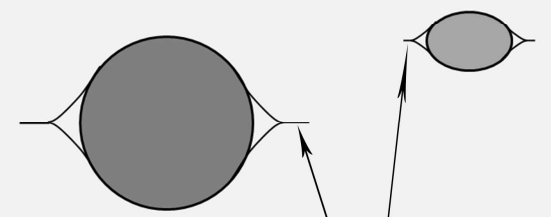

Self-welding
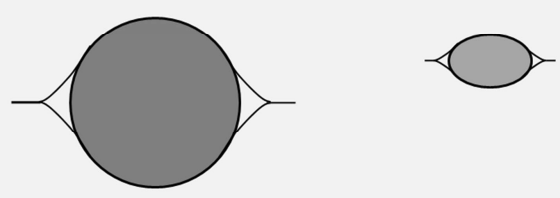


\title{
Response of oxide nanoparticles in an oxide dispersion strengthened steel to dynamic plastic deformation
}

\author{
Zhenbo Zhang $^{1 *}$, Wolfgang Pantleon ${ }^{2}$ \\ ${ }^{1}$ School of Materials, University of Manchester, Manchester, M13 9PL, UK \\ ${ }^{2}$ Section of Materials and Surface Engineering, Department of Mechanical \\ Engineering, Technical University of Denmark, 2800 Kgs. Lyngby, Denmark
}

\begin{abstract}
The behaviour of oxide nanoparticles in an oxide dispersion strengthened (ODS) steel subjected to dynamic plastic deformation (DPD) was investigated by transmission electron microscopy (TEM) and high resolution TEM (HRTEM). Contrary to the motivation for dispersing oxides in a ferritic matrix that the hard particles would be non-deformable and constitute obstacles of plastic deformation, it is discovered that oxide nanoparticles with sizes smaller than $20 \mathrm{~nm}$ were appreciably deformed to an average equivalent strain of 1.2 in the sample after DPD to a strain of 2.1. The plastic distortion of the oxide nanoparticles by compression increases with the externally applied strain. HRTEM analysis demonstrates that deformation twinning is the dominant mechanism of plastic deformation for the oxide nanoparticles. In addition, experimental results show that the deformation of oxide nanoparticles does not only occur at high strain rates, but also at lower strain rates, and does not rely on the interfacial coherency between the oxide nanoparticle and the ferritic steel matrix. Due to the incompatible deformation between the oxide nanoparticles and matrix, nanoscale voids form at their interface during deformation at low strains, and evolve with increasing deformation in distinctively different manner around larger and smaller particles. The reasons for the size effect on the deformation of oxide nanoparticles and on the co-deformation between oxide nanoparticles and ferritic matrix in the ODS steel are discussed.
\end{abstract}

Key words: ODS steel; plastic deformation; oxide nanoparticles; deformation mechanism; decohesion

*Corresponding author (Z.B.Zhang)

E-mail address: zhenbo.zhang@ manchester.ac.uk; zbzhang85@gmail.com 


\section{Introduction}

Oxide dispersion strengthened (ODS) steels are promising structural materials for the blanket component in fusion reactors $[1,2]$. The oxide nanoparticles, which are well dispersed in the steel matrix, are essential to maintain the strength of ODS steels at high temperatures and to accomplish excellent irradiation tolerance of ODS steels [1]. It is well documented that oxide nanoparticles form by re-precipitation during hot consolidation of the severely ball-milled mixtures of yttria and pre-alloyed iron powders [3]. Consequently, in manufactured ODS steels, the oxide nanoparticles are no longer consisting of only yttrium and oxygen, i.e. not pure yttria anymore, but alloyed with other elements from the steel matrix. Due to the significance of the oxide nanoparticles, oxide nanoparticles have been extensively studied with respect to their composition, crystallographic structure and interface with iron matrix [4-12]. In general, for ODS steels containing aluminium, the oxide nanoparticles are found to be yttrium-aluminium oxide [4-8]; whereas in ODS steels without aluminium but with titanium, the oxide nanoparticles are identified as yttrium-titanium oxide [9-12]. Although there are large discrepancies in the reported crystallographic structure of the oxide nanoparticles and their orientation relationship with the matrix even for the same material, the common conception about oxide nanoparticles is that they are both, strong and stable.

Compared to the number of studies on identifying the oxide nanoparticles $[4,6,8$, 9], the interface between oxide nanoparticles and matrix [8, 10-12], the thermal stability and the irradiation performance of various ODS steels [13-16], there are only few results available regarding the behaviour of the oxide nanoparticles when the ODS steels are subjected to plastic deformation. The latter is of high importance, since processing of ODS steels inevitably involves plastic deformation, and any changes in the structure and morphology of the oxide nanoparticles caused by plastic deformation may alter the mechanical properties (and the irradiation tolerance) of ODS steels. Therefore, the main objective of this study is to explore the response of the oxide nanoparticles in a specific ODS steel during plastic deformation and to identify potential changes in size, morphology and structure of the oxide nanoparticles due to a thermomechanical treatment.

In addition, clarifying the behaviour of oxide nanoparticles under loading and plastic deformation is also relevant for understanding the strengthening mechanism of ODS steels. It is well known that the strengthening effect and the efficiency of the dispersoids depend on the character of the dispersoids $[17,18]$. In terms of particle strengthening, two mechanisms related to the interaction of dislocations with either 
penetrable or impenetrable obstacles are distinguished. For hard, impenetrable particles, dislocations are forced to bow out between the particles, forming dislocation loops around them, causing Orowan strengthening [19]. For penetrable particles, dislocations can pass them by cutting through [19]. Oxide nanoparticles in ODS steels are generally thought to be impenetrable and strengthen the steel by the Orowan mechanism [20]. However, direct experimental evidence is lacking. Clarification of the strengthening effect due to the oxide nanoparticles by studying the behavior of oxide nanoparticles during plastic deformation is, hence, another objective of this work.

In this study, an Al-alloyed ODS ferritic steel (PM2000) was plastically deformed with high strain rates to different strains, and the resulting microstructures were characterized in detail by transmission electron microscopy (TEM) and high resolution TEM (HRTEM). Dynamic plastic deformation caused a strong refinement of the ferritic matrix. Remarkably, it is discovered that the oxide nanoparticles became also severely deformed. The plastic deformation mechanism of the oxide nanoparticles and the co-deformation behaviour between the oxide nanoparticles and the ferritic steel matrix were explored in this study. These findings are not only of significance for understanding the behaviour of oxide nanoparticles when ODS steels are processed plastically, but also provide insights into understanding the strengthening mechanisms of ODS steels originating from the oxide nanoparticles.

\section{Experimental}

A ferritic ODS steel, PM2000, with nanoscale oxide dispersoids was acquired in form of a hot-extruded rod with a diameter of $13 \mathrm{~mm}$. The rods have been produced by Plansee, Austria, by powder metallurgy following the procedure described in [21]. The nominal chemical composition is given in Table 1 [22].

Cylindrical specimens having a diameter of $6 \mathrm{~mm}$ and height of $9 \mathrm{~mm}$ were machined with their cylinder axis along the initial extrusion direction. Compression of these cylinders was carried out by dynamic plastic deformation (DPD) [23] at room temperature with a strain rate of about $10^{2}-10^{3} \mathrm{~s}^{-1}$ with the equipment available at Institute of Metal Research of the Chinese Academy of Science in Shenyang. Samples used in this study were deformed to equivalent strains of 0.6, 1.0, 1.6, and 2.1, which are reached by two, three, four and five strokes, respectively. To reveal the effect of strain rate on the behavior of the oxide nanoparticles, samples with same dimensions were alternatively compressed by quasi-static compression (QSC) with an initial strain rate of $10^{-4} \mathrm{~s}^{-1}$. To clarify the potential effect of interfacial coherency on the behavior of oxide nanoparticles, some samples were annealed at $1200{ }^{\circ} \mathrm{C}$ for 1 hour to 
ensure that the interface between oxide nanoparticles and matrix became arbitrary in these samples [8]. These latter samples were then compressed by DPD to a strain of 2.1. Detailed microstructural characterizations were conducted on all samples.

The microstructure of the as-received and DPD samples was analyzed by means of a JEOL 2000FX transmission electron microscope. Additionally, energy dispersive X-ray spectroscopy (EDX), high resolution transmission electron microscopy (HRTEM) and scanning transmission electron microscopy (STEM) studies of nanoparticles were carried out using a JEOL 3000F microscope operating at $300 \mathrm{kV}$. TEM foils were prepared by twin jet electropolishing followed by a cleaning process by ion milling. For identification of the crystal structure of the nanoparticles, oxide nanoparticles were extracted by carbon replica. The CaRine Crystallography 3.1 software was used to construct the crystal structure of the oxide nanoparticles and simulate the diffraction patterns and the effect of deformation-induced defects on them.

\section{Results}

\subsection{Initial microstructure}

The bright field TEM image in Fig. 1a shows the microstructure in a longitudinal section of the as-received PM2000. The as-received material is characterized by nearly equiaxed subgrains and a high dislocation density. A TEM image with higher magnification (Fig. 1b) reveals the morphology and distribution of oxide nanoparticles in this ODS steel: The oxide particles are nearly spherical, welldispersed in the ferritic steel $(\alpha-\mathrm{Fe})$ matrix and have a mean diameter of $14 \mathrm{~nm}$ [8]. HRTEM images (Figs. 1c and 1d) show the crystallographic structure of the oxide nanoparticles and their orientation relationship with the matrix. The oxide nanoparticles have been indentified as orthorhombic $\mathrm{YAlO}_{3}$ (YAP, yttrium aluminium perovskite) with a near cuboid-on-cube orientation relationship with the matrix [8].

\subsection{Microstructure after compression by DPD to a strain of 2.1}

Bright field TEM images of a sample after compression by DPD to a strain of 2.1 are shown in Figs. 2a and $2 \mathrm{~b}$. The nearly equiaxed structure of the as-received material is transferred to a nanoscale lamellar structure after deformation (Fig. 2a) [24]. The enlarged image (Fig. 2b) from the framed region shows more microstructural details. It reveals that the deformation microstructure contains elongated features (marked by black arrows), which are aligned almost perpendicular 
to the compression axis. A similar bright field image after compression by DPD is presented in Fig. 2c together with the corresponding dark field TEM image obtained by selecting a diffraction spot from the oxide nanoparticles in Fig. 2d. Those elongated features exhibit a brighter diffraction contrast in this image, which indicates that they very likely are YAP nanoparticles. To gain further evidence, a STEM image of the DPD sample is presented in Fig. 2e. Differently from the diffraction contrast in conventional TEM images, the STEM image mainly reflects the mass contrast, for instance, regions with smaller atomic number and/or including lighter elements, as oxides particles in a steel matrix, appear darker and vice versa. It is evident from the STEM image that the elongated features are darker than the ferritic steel matrix, which indicates that they contain lighter elements than Fe. An EDX line scan (Fig. 2f) obtained from the region marked by the yellow line in Fig. 2e provides support that these features are enriched in $\mathrm{Y}$ and $\mathrm{Al}$, but depleted in $\mathrm{Fe}$ and $\mathrm{Cr}$, which indicates that these features are indeed YAP nanoparticles. Accordingly, these nanoparticles have been transferred from an initial spherical shape to an oblate (disc) shape during compression by DPD, i.e. the oxide nanoparticles were plastically deformed. Almost equiaxed particles with only slight anisotropy were observed from a different section that contains the compression plane [25], which further proved that the initially spherical oxide nanoparticles were deformed into oblates.

\subsection{Analysis of oxide nanoparticles after DPD}

The oblate shapes of the oxide nanoparticles reflect the plastic deformation they underwent. To evaluate the plastic strain experienced by the oxide nanoparticles during DPD, their aspect ratio (AR) in the longitudinal section is determined from bright field TEM images. Statistical data illustrating the relationship between the particle size reported as equivalent circular diameter (ECD) and the aspect ratio are obtained from 160 and 240 particles in the samples after compression by DPD to macroscopic strains of 1.0 and 2.1, respectively, and provided in Figs. 3a and 3b. These plots reveal three important findings: (i) the AR of oxide nanoparticles increases with increasing macroscopic strain; (ii) the AR tends to increase with decreasing particle size; and (iii) most of the particles with AR larger than 1.2 have ECDs less than $20 \mathrm{~nm}$. The latter results can further be substantiated by comparing the frequencies of particles with an ECD below $20 \mathrm{~nm}$ in the as-received and the DPD samples. After DPD to a macroscopic strain of 1.0 or 2.1 , the percentage of such small particles with an aspect ratio below 1.2 after DPD is $48 \%$ or $12 \%$, respectively, which is substantially smaller than the frequency of $74 \%$ of such non-elongated, almost equiaxed particles of this size in the as-received condition. The distributions of the aspect ratios for all particles with AR larger than 1.2 in the sample after DPD to 
strains of 1.0 and 2.1 are presented in Figs. 3c and 3d. A large variation of the AR can be seen in both cases from the standard deviations (St. Dev.) of $0.8 \mu \mathrm{m}$ and $2.1 \mu \mathrm{m}$, while the mean AR for particles with AR above 1.2 being $2.8 \mu \mathrm{m}$ and $6.3 \mu \mathrm{m}$ after DPD to strains of 1.0 and 2.1, respectively.

Considering that the oxide nanoparticles had a nearly equiaxed shape before DPD, particles with aspect ratios larger than 1.2 are considered to have plastically deformed during compression by DPD. The true plastic strain of the particles after deformation is estimated from their aspect ratio as $\varepsilon_{\text {part }}=2(\ln A R) / 3$ assuming spherical shapes before compression. The plastic strain calculated using this relation is shown in Fig. 3e and $3 \mathrm{f}$ for all particles with AR larger than 1.2, i.e. for the presumably deformed particles only. The plastic strain varies considerably from particle to particle with a mean value of the equivalent plastic strain of the oxide nanoparticles of 0.7 and 1.2 for the samples deformed by DPD to macroscopic strains of 1.0 (Fig. 3e) and 2.1 (Fig. 3f), respectively. Obviously, the average equivalent strain of the particles is substantially smaller than the macroscopic strain.

\subsection{Deformation mechanism of the oxide nanoparticles}

For gaining insight into the deformation mechanisms, the deformed oxide nanoparticles were characterized by HRTEM at an early stage, i.e. after compression by DPD to the low macroscopic strain of 0.6. Two examples of deformed YAP particles are presented and analyzed in Fig. 4. The HRTEM image and corresponding FFT and IFFT (Fig. 4a) show the existence of deformation twins in the deformed nanoparticle; the twin boundaries are indicated by the yellow lines in the HRTEM image and IFFT image. According to the FFT pattern, the deformation twins can be indexed as (110)[112], i.e. the twinning plane and twinning direction are (110) and [1 12], respectively. A simulated scheme of the atomic structure of (110)[112] twinning in YAP viewed along the [111] zone axis is shown in Fig. 5 (structure I); it is in a very good agreement with the observed structure in Fig. 4a.

Another example of a deformed YAP nanoparticle is shown in Fig. 4b. One twin boundary with the same twin character as that in Fig. 4a (110)[112]) is marked by yellow lines. In addition, another planar defect (indicated by blue lines) is observed in the same particle parallel to the twin boundary. As seen from the HRTEM and IFFT images, this defect resembles a stacking fault in metallic materials. In a pure metal, a stacking fault involves only a single plane of displaced atoms, i.e. it is a two dimensional defect. Whereas, for YAP, one lattice plane in the HRTEM image corresponds to an entire periodical unit of atoms with a certain width. Therefore, the defect cannot be addressed as stacking fault. The schematic diagram (structure II in 
Fig. 5) illustrates the atomic structure of this defect. Evidently, several planes of atoms are present in the defect, and these planes (as marked in the dashed rectangle) have mirror relationship with the mother crystals on both sides. Therefore, the particular defect marked by blue lines is actually considered to be a deformation twin with the same character (twinning plane and twinning direction are (110) and [112], respectively), as those indicated by yellow lines. The only difference is that this twin involves only three (110) lattice planes seen from the HRTEM image, i.e. the twin unit with minimum thickness which can form in a YAP crystal. It should be mentioned here that (110)[112] twins were frequently observed in slightly deformed YAP nanoparticles, and no evidence of any other type of defects was found in them. Therefore, it is suggested that (110)[1 12 ] deformation twinning is the dominant deformation mechanism for YAP nanoparticles, at least when compressed to low strains.

Deformed YAP nanoparticles were characterized also in the sample after DPD to a strain of 1.6, and two examples are presented in Figs. 6a and 6b. Due to the high density of defects in these particles and the strong interference from the severely deformed matrix, no clear HRTEM lattice images of the particles can be obtained. Nevertheless, useful information is derived from these images: the particles are still crystalline and no amorphous or phase transformation occurs in these particles, as otherwise frequently observed in perovskite materials under high pressure [26-28].

3.5 Co-deformation behaviour between oxide nanoparticles and the matrix

Since the oxide nanoparticles are embedded in the ferritic steel matrix, stress and strain are directly imposed on the YAP nanoparticles by the surrounding matrix, and the combined deformation between the YAP and Fe becomes significant for understanding the deformation behavior of the oxide nanoparticles. Thus the evolution of the shape of the oxide nanoparticles and their surrounding matrix with strain during DPD is characterized in more detail to further clarify the deformation mechanism of this ODS steel.

The TEM images in Fig. 7 show the microstructure in the longitudinal section of samples after DPD to four different macroscopic strains, namely 0.6, 1.0, 1.6 and 2.1. It is seen in Fig. 7a that after deformation to a macroscopic strain of 0.6 , all oxide particles still appear spherical and no appreciable deformation of the oxide particles can be observed yet. Interestingly, small voids on a nanoscale (marked by arrows) are seen in this section at the interface on both sides of the nanoparticles. These nanovoids are presumed to extend in the compression plane and form a toroidal girdle around the entire nanoparticle. Their existence indicates decohesion between the 
oxide nanoparticles and the ferritic steel matrix. With increasing strain to 1.0, the oxide nanoparticles were slightly deformed to an oblate shape and nanovoids are still present at the interface. After DPD to a strain of 1.6 (Fig. 7c), the YAP particles are further elongated, whereas nanovoids around some of the smaller YAP particles disappear. Nanovoids around relatively large particles, on the contrary, are still present. In the sample after DPD to a strain of 2.1 (Fig. 7d), the oxide nanoparticles are deformed severely and most of the nanovoids at the interface disappeared.

The above observations suggest that nanovoids developed around smaller particles heal during further deformation, whilst those around larger particles do not close. Further evidence for such a behavior is presented in Figs. $8 \mathrm{a}$ and $8 \mathrm{~b}$. It is seen from Fig. 8a that in the sample after DPD to a macroscopic strain of 1.0, nanovoids form not only around large particles with size larger than $20 \mathrm{~nm}$, but also around small YAP particles with sizes less than $20 \mathrm{~nm}$ (ECD about $8 \mathrm{~nm}$ ), which are indicated by red arrows. After DPD to a strain of 2.1 , nanovoids around small particles have disappeared accompanying the plastic deformation of the particles and accommodating their forming oblate shape (see the white arrows in Fig. 8b). Nanovoids around relatively larger particles (indicated by red arrows in Fig. 8b) with sizes larger than $20 \mathrm{~nm}$, on the other hand, are preserved after deformation to such a high strain. These larger oxide nanoparticles almost do not change their initial spherical shape.

Additional evidence for unclosed voids at the interface around a large oxide nanoparticle is presented in Fig. 6c. The HRTEM image shows an oxide nanoparticle with nanovoids at the interface in the sample after DPD to a strain of 2.1. The YAP particle has an ECD of approximately $30 \mathrm{~nm}$. No appreciable deviation from spherical shape and hence no plastic deformation is revealed for it; no deformation-induced defects are visible in the particle either. As indicated by white arrows, nanovoids caused by debonding are still present at the YAP/Fe interface.

3.6 Effect of interfacial coherency on the behaviour of oxide nanoparticles

The interface between the oxide nanoparticles and the ferritic steel matrix may play a certain role for the evolution of the matrix and oxide particles and their codeformation, since stresses and strains are transferred from the matrix to the particles via the interface, and formation of toroidal voids around the particles results from debonding of the interface. These processes are potentially related to the character of the interface, its interfacial energy and bonding strength. In general, there are three different types of interface character, namely coherent, semi-coherent and incoherent interfaces. For the as-received PM2000, the interface between the YAP nanoparticles 
and the matrix is proven to be coherent [8]. As shown in the previous section, substantial deformation of YAP nanoparticles occurs during compression by DPD. This naturally invokes the question, whether the nanoparticles can be plastically deformed or not, if they have a different type of interface with the matrix as, for instance, an incoherent interface.

Thus, by annealing at $1200{ }^{\circ} \mathrm{C}$ for 1 hour, a sample in which oxide nanoparticles have an arbitrary interface with the matrix is prepared and compressed by DPD. It is observed that even for this coarse grained material a very fine lamellar structure is formed after DPD to a strain of 2.1 [25]. More importantly many black features, similar to the ones seen in the Fig. 2, are observed. Accordingly, these black features are deformed oxide nanoparticles as well. It becomes also evident, that the considerably deformed oxide nanoparticles are those with sizes less than $20 \mathrm{~nm}$. Nanovoids are observed around undeformed oxide nanoparticles in this sample (Fig. 8d), whereas no voids are detected at the substantially deformed oxide nanoparticles (Fig. 8c). Therefore, it can be concluded that the oxide nanoparticles are substantially deformed during DPD independent of their interface with the ferritic steel matrix (either coherent or incoherent).

\subsection{Effect of strain rate on the deformation of oxide nanoparticles}

As the novel finding of plastic deformation of oxide nanoparticles is neither a common place, nor has it been reported previously, it is ought to be clarified whether the deformation of oxide nanoparticles is related to the high strain rates imposed by DPD or not by investigating a sample compressed quasi-statically with a low strain rate of $10^{-4} \mathrm{~s}^{-1}$. A TEM image of the microstructure of a sample after quasi-static compression (QSC) to a strain of 2.1 is presented in Fig. 8e and 8f. A nanoscale lamellar structure developed after deformation, and more importantly deformed oxide nanoparticles are also observed. The average aspect ratio of the deformed oxide nanoparticles (i.e. with aspect ratios above 1.2) in the sample after QSC to 2.1 is about 6.2, which is very close to that of their counterparts after compression by DPD (6.3). The nanovoid around the larger particle (about $25 \mathrm{~nm}$ ) indicated by red arrows in Fig. $8 \mathrm{f}$ remained open, whereas no voids are observed around the smaller particles. Therefore, the deformation of oxide nanoparticles occurs not only at high strain rates during DPD, but also during QSC at a much lower strain rate. .

\section{Discussion}

\subsection{Deformation of YAP nanoparticles by twinning}


Particles or precipitations strengthen metallic materials by hindering the motion of dislocations. For metallic materials with second phase precipitates, dislocations interact with the precipitates either by cutting through the precipitate or forming Orowan loops around it [19,29]. Relatively hard particles such as oxides and carbides in steels are considered to be unable to be sheared by gliding dislocations [30]. Shearing of precipitates by matrix dislocations generally requires coherency and a particular orientation relationship between the lattices of precipitate and matrix. For the investigated PM2000, however, the plastic deformation of oxide nanoparticles does not rely on interfacial coherency, which suggests that shear caused by gliding dislocations is not the cause for their deformation. In addition, twin lamellae rather than dislocations are frequently observed in the deformed oxide nanoparticles providing strong evidence for a twinning dominated mechanism for the observed plastic deformation of the oxide nanoparticles in PM2000.

For strengthening of steels by oxide dispersoids, oxide nanoparticles are generally considered as hard objects experiencing only minor elastic strains, while plastic deformation is completely neglected for such nanoparticles [31, 32]. Established models for the strengthening mechanism and the interaction of dislocations with the oxide nanoparticles are entirely based on this well-accepted premise (e.g. [33]). The present investigation, however, demonstrates (i) that oxide nanoparticles in PM2000 actually deform plastically and (ii) that they are able to sustain rather high plastic strains during deformation at room temperature, especially those with sizes smaller than $20 \mathrm{~nm}$. In view of these observations, it seems indispensable for an understanding of the strengthening mechanism in ODS steels to take the effect of potential plastic deformation of oxide nanoparticles into consideration.

Twinning is commonly observed in materials with perovskites structures, such as $\mathrm{BaTiO}_{3}$ [34], $\mathrm{CaTiO}_{3}$ [35], $\mathrm{SrTiO}_{3}$ [36], etc. For orthorhombic perovskites, twin domains that are related by mirror operations with respect to (112) and (110) planes are reported for $\mathrm{MgSiO}_{3}$ [37] and $\mathrm{LaGaO}_{3}$ [38]. In these perovskites, the occurrence of growth twins and transformation twins related to changes in pressure and/or temperature are well documented [37]; mechanical twinning, however, is much less understood compared to transformation twinning in perovskites. Nevertheless, twinning of a tetragonal perovskite $\left(\mathrm{BiTiO}_{3}\right)$ along (110) planes was observed after nanoindentation [39], and twinning along (110) planes was also found in an orthorhombic perovskite (YAP) after creep tests at $0.82-0.88$ of the melting temperature [40]. Such an occurrence of deformation twins in bulk perovskite material is considered to be similar to that observed in the deformed YAP 
nanoparticles. Where dislocations with a variety of Burgers vectors were found in the bulk YAP after creep test at high temperatures [40], no dislocations were observed in the YAP nanoparticles after compression by DPD at room temperature, presumably because dislocations in perovskites are thought to be mobile only at high temperatures $[41,42]$.

With increasing the externally applied strain, the plastic deformation of oxide nanoparticles increases; the estimated strain of oxide nanoparticles, however, remains always below the macroscopic applied strain. For macroscopic strains up to 0.6, no appreciable deformation of the oxide nanoparticles is detected. This indicates that maintaining compatibility is not the key reason for the plastic deformation of the nanoparticles; deformation the of oxide nanoparticles commences when the strength of the surrounding matrix has increased by work-hardening substantially, so that the stress level in the matrix is large enough to impose sufficient stresses on the oxide nanoparticles. On the other hand, the deformation of YAP nanoparticles is not sensitive to the applied strain rate in the range investigated in the present work (from $10^{-4} \mathrm{~s}^{-1}$ to $10^{2} \mathrm{~s}^{-1}$ ), which suggests that it is a rather general behavior for PM2000 compressed at room temperature.

\subsection{Size dependent deformation of YAP nanoparticles}

A strong size dependence of the plastic deformation of oxide nanoparticles has been discovered with only particles with sizes smaller than $20 \mathrm{~nm}$ undergoing appreciable deformation. To clarify whether large YAP particles undergo a different deformation mechanism from that of smaller particles, HRTEM characterization was conducted on a few large YAP particles which showed evidence for plastic deformation. Due to the fact that particles of sizes larger than $20 \mathrm{~nm}$ were seldom deformed, it is not easy to obtain information on the deformation mechanism for large particles. One example from a sample deformed to a strain of 2.1 showing an only slightly elongated and, hence, only slightly deformed YAP particle with a diameter of about $26 \mathrm{~nm}$ is presented in Fig. 9. From Fig. 9a, it is seen that this YAP particle contains several defects. An enlarged IFFT image (Fig. 9b) reveals a deformationinduced coherent boundary. The boundary is not straight but zigzagging, and the coherent plane is $(020)_{\text {YAP. }}$ The right side of the boundary is identified to be YAP with the incident electron beam along [100] YAP. However, the left side of the boundary cannot be indexed as YAP along any zone axis. After comparing with all possible yttrium aluminium oxides, the crystalline lattice of the present phase can be identified as hexagonal $\mathrm{YAlO}_{3}$ (yttrium aluminium hexagonal, YAH) inspected along its [221] direction. YAH has the same composition as YAP, but a different 
crystallographic structure. Thus, the YAH regions suggested to be a transformationinduced product transformed from YAP during DPD. In addition, as seen from the image in Figs. 9c and 9d, this phase transformation involves a change in the interface between the nanoparticle and the ferritic steel matrix. Between the retained YAP and the matrix, the lattice is still coherent with $(220)_{\mathrm{YAP}} / /(110)_{\alpha}$ (Fig. 9c), which is identical to the orientation relationship in the undeformed sample. However, after the transformation, the newly formed YAH does not have any coherent lattice with the matrix (Fig. 9d). Such pressure induced phase transformations are common in materials with perovskite structure [27]. For bulk YAP with orthorhombic perovskite structure, several possible pressure-induced phase transformations have been examined [28].

The observation on the large nanoparticle in Fig. 9 indicates that deformationinduced phase transformation is the main deformation mechanism for YAP nanoparticles larger than $20 \mathrm{~nm}$, in contrast to the twining-dominated deformation of smaller particles. This difference in deformation mechanism is considered to be the underlying reason for the size-dependent deformation behavior of YAP oxide nanoparticles, with smaller particles being more prone to deform than larger particles. Where the physical reason for such a change in the deformation mechanism of YAP depending on the particle size remains unclear, a qualitative understanding of the size effect can be gained based on thermodynamic considerations. The polymorphic phase transformation of the nanoparticles from stable YAP to metastable YAH under mechanical loading is facilitated by the concurrent plastic deformation of the nanoparticle lowering the internal elastic stresses and, hence, reducing the total elastic energy. The simultaneous formation of a phase boundary between YAP and YAH and the necessary boundary energy dominate the energy balance for small particles and suppress the occurrence of the phase transformation in small nanoparticles. This is in marked contrast to twinning which may occur in nanoparticles owing to generally rather low boundary energies of twin boundaries. A similar occurrence of twinning instead of a (martensitic) phase transformation has been reported for nanocrystals of ordered B2 phase CuZr [43]. The outlined thermodynamic argument does not account for the required critical resolved shear stress and the kinetics of both process which may render twinning of larger particles infeasible. Further characterization on an atomic scale combined with multiscale simulation is desired to uncover the underlying reason for such a size dependence on the deformation behavior of YAP nanoparticles entirely.

\subsection{Nanovoids at YAP/matrix interface}


As shown in the present study, voids on the nanoscale are generated around YAP nanoparticles in the ODS steel PM2000 during DPD. Formation of voids adjacent to non-metallic particles was previously reported in steels after rolling at low and high temperatures [44-47]. From a systematic study of the deformation behavior of $\mathrm{MnS}$ in steels, Charles et al. [44, 45] claimed that the formation of voids around the particle/matrix interface is caused by the inability of the steel matrix to flow around the particles and simultaneously maintain in contact with them. If the interfacial strength is not sufficient to withstand the tensile stresses due to the deformation of matrix, decohesion between particles and matrix takes place, thereby forming a toroidal void at the interface. Waudby et al. [46] considered that decohesion is initiated by frictional forces acting tangentially to the surface of the inclusion. Combined with the force imposed by the flow of steel matrix, toroidal voids are created. Employing a finite element method, Luo et al. [47] proposed that debonding would occur if the resolved normal stress at the interface reaches a critical value. Despite slight discrepancies in the formation mechanism of voids around non-metallic particles proposed by different researchers, there is a general agreement that it is the local heterogeneous flow due to the discontinuity at the interface between the particles and the matrix that causes the formation of voids. Consequently, the difference in yield stress between particles and matrix is the common reason for void initiation adjacent to the interface.

In the as-received steel PM2000, the ferritic matrix is much softer than the oxide nanoparticles. Therefore nanovoids form adjacent to the particle after compression by DPD to a strain of 0.6. With increasing strain, the matrix is work-hardened, and once the yield stress of the matrix is comparable to that of the YAP nanoparticles, the particles start to deform simultaneously with the matrix by a similar extent. During this process, nanovoids around deformable oxide nanoparticles close, while nanovoids associated with those particles that do not deform considerably still remain open. A comparison between the strains of YAP nanoparticles and the ferritic steel matrix verifies this claim: The average strain experienced by the particles (as estimated from their shape change) increases with increasing macroscopic strain, remaining always smaller than the imposed macroscopic strain. It should be mentioned that for spherical particles subjected to compression to strains of 1.0 and 2.1, an aspect ratio of 4.5 and 23.3 is expected, respectively. Apparently, the average values obtained for the YAP particles in the present experiment, 0.7 and 1.2, are much smaller than these values.

A series of schematic diagrams (Fig. 10) shows the envisaged evolution of nanovoids around the oxide nanoparticles with strain coupled to the deformation of the oxide nanoparticles themselves. There are two categories of oxide nanoparticles in 
the matrix, namely small particles with sizes smaller than $20 \mathrm{~nm}$ which are substantially deformed during DPD, and large particles with sizes larger than $20 \mathrm{~nm}$ which do not deform appreciably with increasing strain. Debonding occurs at the YAP/matrix interface along a great circle (of the special nanoparticles) in the compression plane, where tensile normal stresses are the largest. Thereby voids having sizes proportional to the sizes of the particle form at the interface (Fig. 10b). Self-welding [44, 45] of the matrix close to the void tip takes place with the emergence of matrix flow from above and below the particle after deformation to a certain strain (Fig. 10c), resulting in the formation of toroidal nanovoids. Progressively, the volume of the voids at the interface decreases with increasing external strain during DPD. Simultaneously, small YAP nanoparticles are plastically deformed, while large particles do not deform. After DPD to high strains (Fig.10d), nanovoids around the small oxide nanoparticles shrink and vanish due to self-welding when the particles are substantially deformed, whereas the nanovoids around the particles that are not considerably deformed are still open. This suggests that the deformation of oxide nanoparticles is crucial for healing of the nanovoids.

It should be noted that the YAP nanoparticles investigated here are much smaller than non-metallic particles in steels [44, 45] (which are typical of micrometer size). The formation of voids due to debonding at the YAP/matrix interface is not naturally expected for ODS steels with nanoscale oxide particles. However, in the present study voids are observed even around YAP particles smaller than $4 \mathrm{~nm}$ after compression at both high strain rates and low strain rates. As the appearance of nanovoids affects the creep rate of ODS steels [48], and very likely deteriorates the ductility and irradiation tolerance, further thermomechanical treatment is recommended for ODS steels after any processing involving plastic deformation.

\section{Conclusion}

The response of YAP oxide nanoparticles in PM2000 to dynamic plastic deformation was firstly investigated by extensive TEM and HRTEM characterisation. Their mechanism of plastic deformation and the co-deformation behaviour between the YAP oxide nanoparticles and the ferritic steel matrix were analysed in details. The main findings can be summarized as follows:

1. YAP nanoparticles with sizes smaller than $20 \mathrm{~nm}$ deform plastically and their shape changes from spherical to oblate, whereas larger particles remain stable.

2. The estimated strains of deformed YAP nanoparticles are always smaller than the macroscopic compressive strains applied. 
3. (110)[112] mechanical twinning is found to be the dominant mechanism of plastic deformation for the YAP nanoparticles with size smaller than $20 \mathrm{~nm}$. No evidence for dislocation-mediated plasticity is found.

4. The occurrence of plastic deformation of small YAP nanoparticles is insensitive to the strain rate and does not rely on the interfacial coherency between YAP and the matrix.

5. Nanoscale voids form at the interface between YAP and the ferritic steel matrix when deformed up to small strains. Most voids around nanoparticles with sizes smaller than $20 \mathrm{~nm}$ are closed after DPD to high strain, whereas voids around the larger, undeformed particles remain still open after DPD to a strain of 2.1.

6. The size-dependent deformation behaviour of YAP oxide nanoparticles is attributed to the different deformation mechanisms of YAP particles with small and large size, i.e. deformation twinning and deformation-induced phase transformation, respectively.

\section{Acknowledgement}

Financial support from the Sino-Danish Center for Education and Research is gratefully acknowledged. The authors also gratefully acknowledge critical discussions of the results with Dr. Oleg Mishin and the support from Dr. Nairong Tao when performing dynamic plastic deformation at Institute of Metal Research, CAS, China.

\section{References}

[1] G.R. Odette, M.J. Alinger, B.D. Wirth. Recent developments in irradiationresistant steels. Annu. Rev. Mater. Res., vol. 38. 2008. pp. 471-503.

[2] I. Chant, K.L. Murty, Structural materials issues for the next generation fission reactors, JOM 62 (2010) 67-74.

[3] M.J. Alinger, G.R. Odette, D.T. Hoelzer, On the role of alloy composition and processing parameters in nanocluster formation and dispersion strengthening in nanostructured ferritic alloys, Acta Mater. 57 (2009) 392-406.

[4] M. Klimenkov, A. Moslang, R. Lindau, EELS analysis of complex precipitates in PM 2000 steel, Eur. Phys. J- Appl. Phys. 42 (2008) 293-303.

[5] L.L. Hsiung, M.J. Fluss, S.J. Tumey, B.W. Choi, Y. Serruys, F. Willaime, A. Kimura, Formation mechanism and the role of nanoparticles in Fe-Cr ODS steels developed for radiation tolerance, Phys. Rev. B 82 (2010). 
[6] C.H. Zhang, A. Kimura, R. Kasada, J. Jang, H. Kishimoto, Y.T. Yang, Characterization of the oxide particles in Al-added high-Cr ODS ferritic steels, J. Nucl. Mater. 417 (2011) 221-224.

[7] P. Dou, A. Kimura, T. Okuda, M. Inoue, S. Ukai, S. Ohnuki, T. Fujisawa, F. Abe, Polymorphic and coherency transition of Y-Al complex oxide particles with extrusion temperature in an Al-alloyed high-Cr oxide dispersion strengthened ferritic steel, Acta Mater. 59 (2011) 992-1002.

[8] Z. Zhang, W. Pantleon, Oxide nanoparticles in an Al-alloyed oxide dispersion strengthened steel: crystallographic structure and interface with ferrite matrix, Philos. Mag. 97 (2017) 1824-1846.

[9] A. Hirata, T. Fujita, Y.R. Wen, J.H. Schneibel, C.T. Liu, M.W. Chen, Atomic structure of nanoclusters in oxide-dispersion-strengthened steels, Nat. Mater. 10 (2011) 922-926.

[10] J. Ribis, Y. de Carlan, Interfacial strained structure and orientation relationships of the nanosized oxide particles deduced from elasticity-driven morphology in oxide dispersion strengthened materials, Acta Mater. 60 (2012) 238252.

[11] C.A. Williams, E.A. Marquis, A. Cerezo, G.D.W. Smith, Nanoscale characterisation of ODS-Eurofer 97 steel: An atom-probe tomography study, J. Nucl. Mater. 400 (2010) 37-45.

[12] Y. Wu, E.M. Haney, N.J. Cunningham, G.R. Odette, Transmission electron microscopy characterization of the nanofeatures in nanostructured ferritic alloy MA957, Acta Mater. 60 (2012) 3456-3468.

[13] N.V. Luzginova, H.S. Nolles, P. ten Pierick, T. Bakker, R.K. Mutnuru, M. Jong, D.T. Blagoeva, Irradiation response of ODS Eurofer97 steel, J. Nucl. Mater. 428 (2012) 192-196.

[14] J. Chen, P. Jung, J. Henry, Y. de Carlan, T. Sauvage, F. Duval, M.F. Barthe, W. Hoffelner, Irradiation creep and microstructural changes of ODS steels of different Cr-contents during helium implantation under stress, J. Nucl. Mater. 437 (2013) 432437.

[15] V.d. Castro, M. Briceno, M.L. Jenkins, M. Kirk, S. Lozano-Perez, S.G. Roberts, In-situ Fe + Ion Irradiation of an Oxide Dispersion Strengthened Steel, J. Phys: Conference Series 522 (2014) 012032.

[16] M.K. Miller, D.T. Hoelzer, E.A. Kenik, K.F. Russell, Stability of ferritic MA/ODS alloys at high temperatures, Intermetallics 13 (2005) 387-392.

[17] E. Arzt, Overview no. 130 - Size effects in materials due to microstructural and dimensional constraints: A comparative review, Acta Mater. 46 (1998) 56115626. 
[18] A. Kelly, The Strengthening of Metals by Dispersed Particles, P. Roy. Soc. AMath. Phys. 282 (1964) 63-79.

[19] B. Reppich. Particle Strengthening. Mater. Sci. Technol. Wiley-VCH Verlag GmbH \& Co. KGaA, 2006.

[20] J.H. Schroder, E. Arzt, Weak Beam Studies of Dislocation Dispersoid Interaction in an Ods Superalloy, Scr. Metall. 19 (1985) 1129-1134.

[21] C. Capdevila, H.K.D.H. Bhadeshia, Manufacturing and microstructural evolution of mechanically alloyed oxide dispersion strengthened superalloys, Adv. Eng. Mater. 3 (2001) 647-656.

[22] J.H. Schneibel, M. Heilmaier, W. Blum, G. Hasemann, T. Shanmugasundaram, Temperature dependence of the strength of fine- and ultrafine-grained materials, Acta Mater. 59 (2011) 1300-1308.

[23] Y.S. Li, N.R. Tao, K. Lu, Microstructural evolution and nanostructure formation in copper during dynamic plastic deformation at cryogenic temperatures, Acta Mater. 56 (2008) 230-241.

[24] Z.B. Zhang, N.R. Tao, O.V. Mishin, W. Pantleon, Oxide dispersionstrengthened steel PM2000 after dynamic plastic deformation: nanostructure and annealing behaviour, J. Mater. Sci. 51 (2016) 5545-5555.

[25] Z.B. Zhang, O.V. Mishin, N.R. Tao, W. Pantleon, Evolution of oxide nanoparticles during dynamic plastic deformation of ODS steel, in: S. Fæster, et al. (Eds.), Proc. of the 35th Risø International Symposium on Materials Science: New Frontiers of Nanometals (2014) 423-430..

[26] M. Hemmati, A. Chizmeshya, G.H. Wolf, P.H. Poole, J. Shao, C.A. Angell, Crystalline-amorphous transition in silicate perovskites, Phys. Rev. B 51 (1995) 14841-14848.

[27] H. Thomas, K.A. Müller, Structural Phase Transitions in Perovskite-Type Crystals, Phys. Rev. Lett. 21 (1968) 1256-1259.

[28] X. Wu, S. Qin, Z.Y. Wu, Generalized gradient approximation calculations of the pressure-induced phase transition of YAlO3 perovskite, J. Phys.-Conden. Mat. 18 (2006) 3907-3916.

[29] A.J. Ardell, Precipitation hardening, Metall. Trans. A 16 (1985) 2131-2165.

[30] A.S. Argon, Strengthening Mechanisms in crystal plasticity, in Physical Metallurgy (4 ${ }^{\text {th }}$ Edition by R.W. Cahn, P. Hassen), North-Holland, 1996.

[31] J.D. Eshelby, The determination of the elastic field of an ellipsoidal inclusion, and related problems, P. Roy. Soc. A-Math. Phys. 241 (1957) 376-396.

[32] M. Song, C. Sun, J. Jang, C.H. Han, T.K. Kim, K.T. Hartwig, X. Zhang, Microstructure refinement and strengthening mechanisms of a 12Cr ODS steel processed by equal channel angular extrusion, J. Alloys Compd. 577 (2013) 247-256. 
[33] A. Takahashi, S. Sato, Discrete dislocation plasticity analysis of dispersion strengthening in oxide dispersion strengthened (ODS) steels, J. Cent. South Univ. 21 (2014) 1249-1255.

[34] E.A.D. White, Twinning in barium titanate crystals, Acta Crystallogr. 8 (1955) 845-845.

[35] M. Calleja, M.T. Dove, E.K.H. Salje, Trapping of oxygen vacancies on twin walls of $\mathrm{CaTiO}_{3}$ : a computer simulation study, J. Phys.-Conden. Mat. 15 (2003) 23012307.

[36] A. Buckley, J.P. Rivera, E.K.H. Salje, Twin structures in tetragonal $\mathrm{SrTiO}_{3}$ : The ferroelastic phase transition and the formation of needle domains, J. Appl. Phys. 86 (1999) 1653-1656.

[37] Y.B. Wang, F. Guyot, A. Yeganehhaeri, R.C. Liebermann, Twinning in $\mathrm{MgSiO}_{3}$ perovskite, Science 248 (1990) 468-471.

[38] W.-L. Wang, H.-Y. Lu, 〈111〉 Rotation Twins in an Orthorhombic $\mathrm{LaGaO}_{3}$ Perovskite, J. Am. Ceram. Soc. 90 (2007) 264-271.

[39] Y. Gaillard, A.H. Macias, J. Munoz-Saldana, M. Anglada, G. Trapaga, Nanoindentation of $\mathrm{BaTiO}_{3}$ : dislocation nucleation and mechanical twinning, J. Phys. D-Appl. Phys. 42 (2009).

[40] Z.C. Wang, C. Dupas-Bruzek, S. Karato, High temperature creep of an orthorhombic perovskite - YAlO3, Phys. Earth Planet. In. 110 (1999) 51-69.

[41] P. Besson, J.P. Poirier, G.D. Price, Dislocations in $\mathrm{CaTiO}_{3}$ perovskite deformed at high-temperature: A transmission electron microscopy study, Phys. Chem. Miner. 23 (1996) 337-344.

[42] Z.C. Wang, S. Karato, K. Fujino, High-Temperature Creep of Single-Crystal Strontium-Titanate $\left(\mathrm{SrTiO}_{3}\right)$ - a Contribution to Creep Systematics in Perovskites, Phys. Earth Planet. In. 79 (1993) 299-312.

[43] S. Pauly, S. Gorantla, G. Wang, U. Kühn, J. Eckert, Transformation-mediated ductility in CuZr-based metallic glasses, Nature Mater. 9 (2010), 473-478.

[44] K.B. Gove, J.A. Charles, Further aspects of inclusion deformation, Metals Tech. 1 (1974) 425-431.

[45] T.J. Baker, K.B. Gave, J.A. Charles, Inclusion deformation and toughness anisotropy in hot-rolled steels, Metals Tech. 3 (1976) 183-193.

[46] P.E. Waudby, W.J.M. Salter, Pickerin.Fb, Study of reaction between silicate inclusions and aluminum in molten iron, J. Iron Steel Inst. 211 (1973) 486-492.

[47] C. Luo, Evolution of voids close to an inclusion in hot deformation of metals, Comp. Mater. Sci. 21 (2001) 360-374. 
[48] R. Singh, J.H. Schneibel, S. Dininski, G. Wilde. Grain boundary diffusion of Fe in ultrafine-grained nanocluster-strengthened ferritic steel, Acta Mater., 59 (2011) 1346-1353 
Table 1 Nominal chemical composition (wt. \%) of PM2000.

\begin{tabular}{llllll}
\hline $\mathrm{Cr}$ & $\mathrm{Al}$ & $\mathrm{Ti}$ & $\mathrm{Y}_{2} \mathrm{O}_{3}$ & $\mathrm{C}$ & $\mathrm{Fe}$ \\
\hline 20 & 5.5 & 0.5 & 0.5 & 0.02 & Bal. \\
\hline
\end{tabular}




\section{Figures and captions}
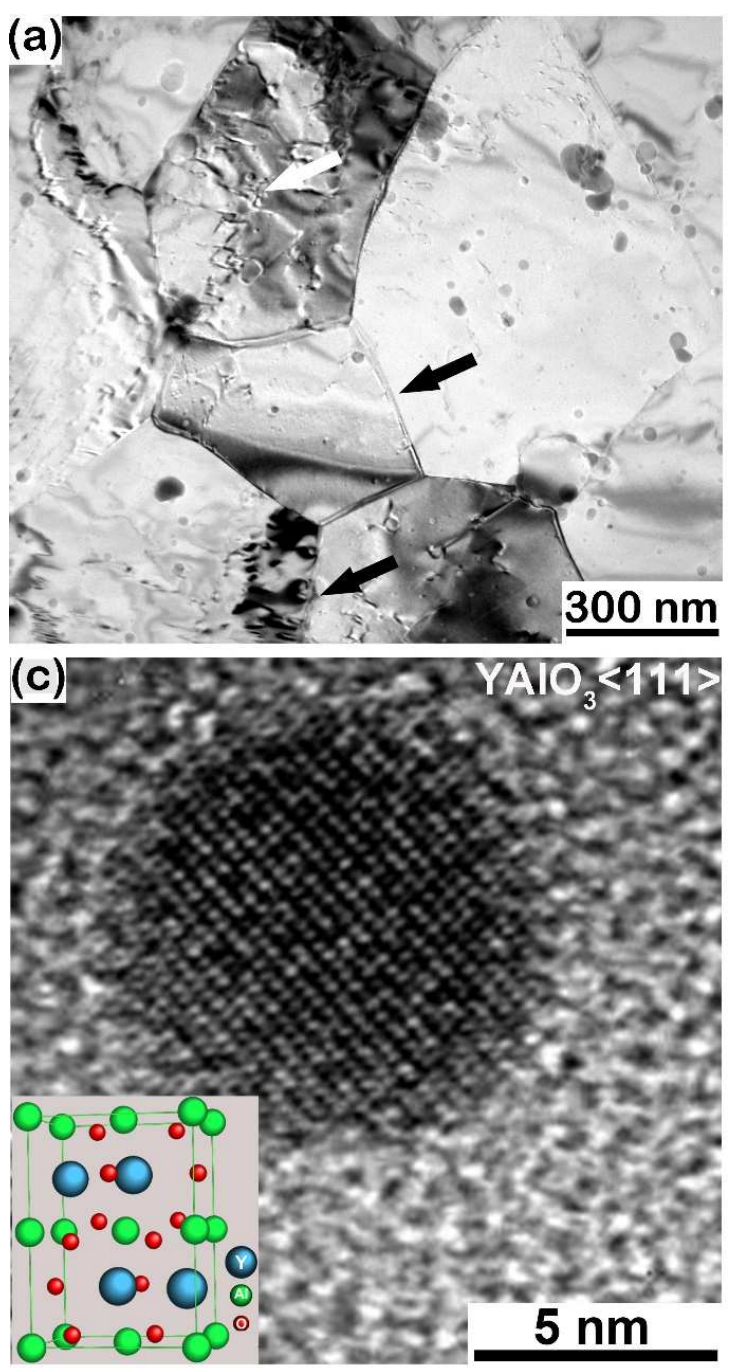
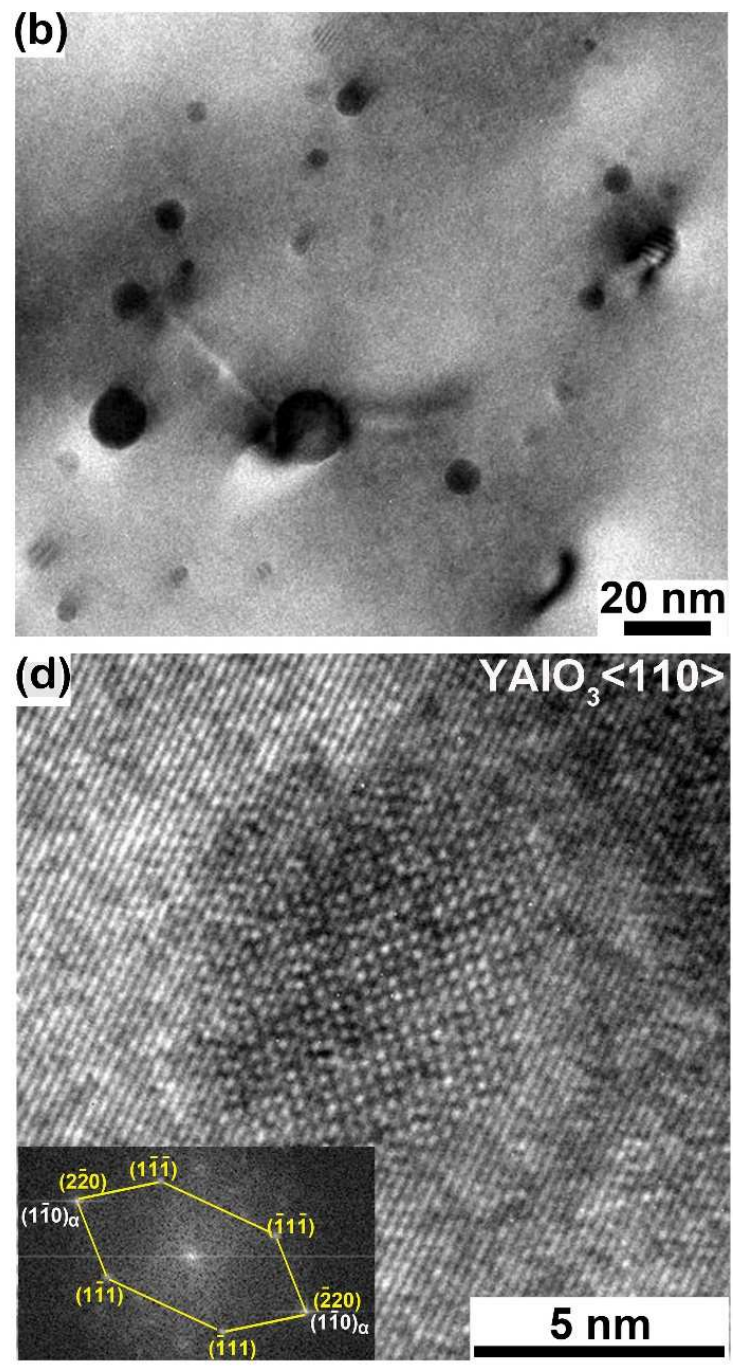

Fig. 1 TEM and HRTEM images from a longitudinal section of the as-received PM2000: (a) a bright field image showing primarily subgrain boundaries (indicated by black arrow) and dislocation structures (indicated by white arrow). (b) a bright field image with higher magnification showing oxide nanoparticles. (c) HRTEM image of an $\mathrm{YAlO}_{3}$ nanoparticle extracted by carbon replica. The electron beam incidents along a $\langle 111\rangle$ zone axis. The inset illustrates the unit cell structure of $\mathrm{YAlO}_{3}$. (d) HRTEM image of both, an $\mathrm{YAlO}_{3}$ nanoparticle and the $\alpha$-Fe matrix with incident beam along a common $\langle 110\rangle$ showing the orientation relationship between them [12]. 

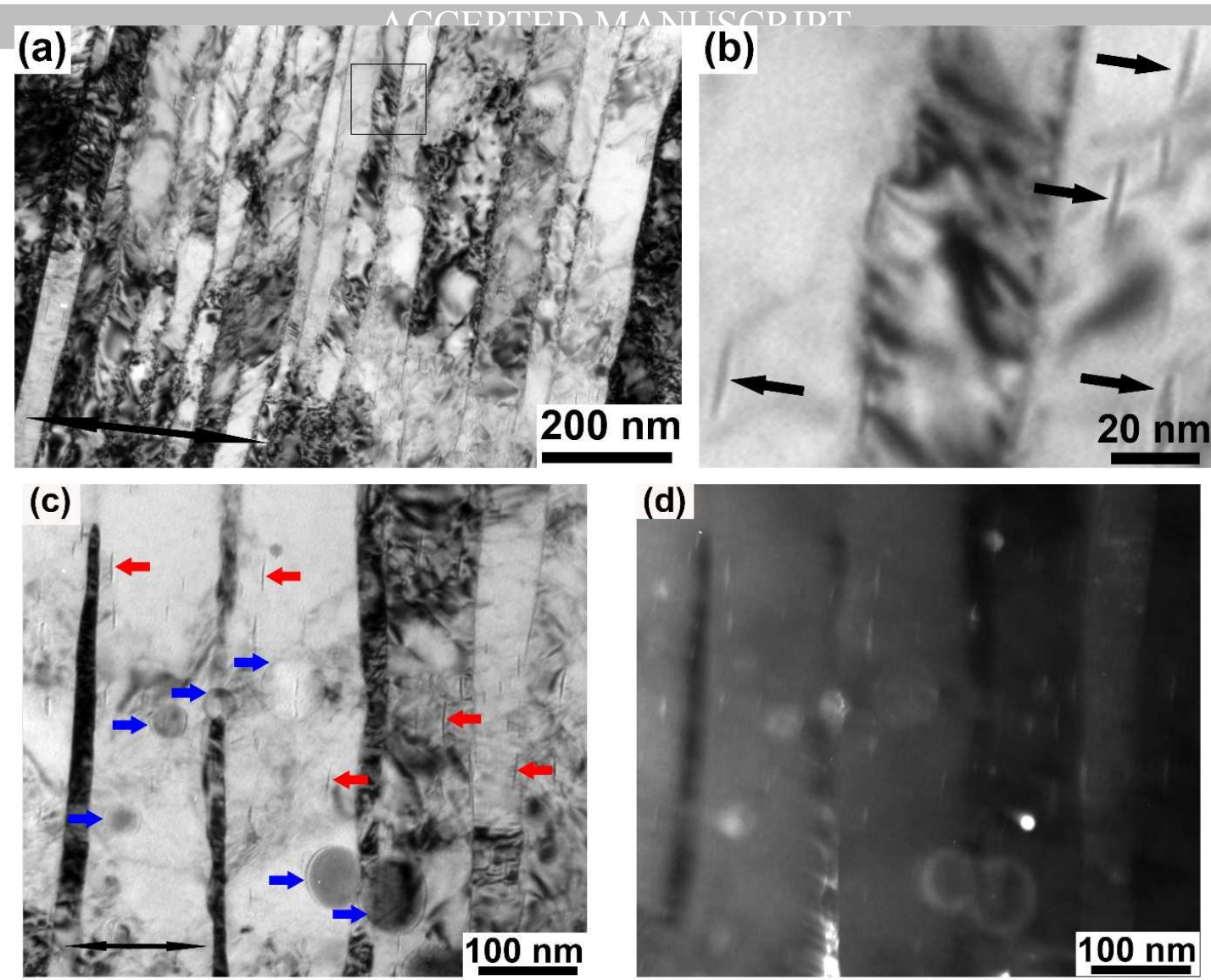

(e)
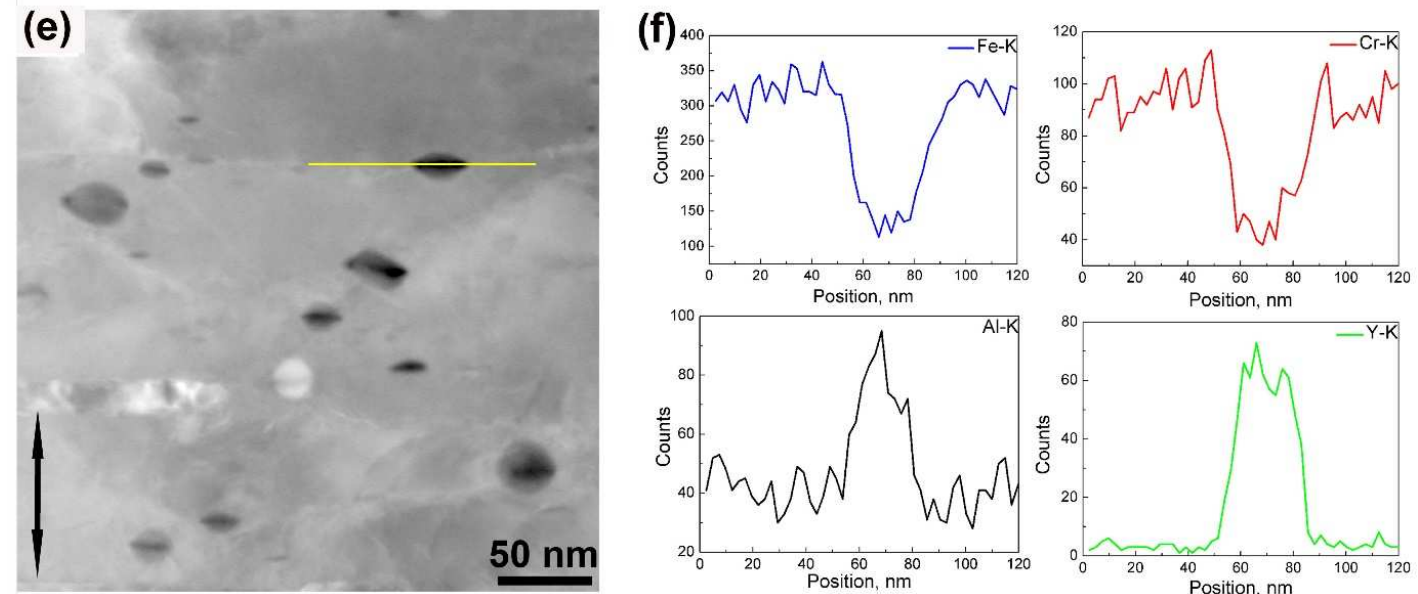

Fig. 2 TEM images from the longitudinal section of PM2000 after compression by DPD to a strain of 2.1: (a) an overview of the deformation microstructure. (b) Magnified image from the framed region in (a). Some black features are indicated by black arrows. (c) Bright field TEM image and (d) corresponding dark field TEM image with diffraction from oxide nanoparticles. Some quite elongated oxide particles are marked by red arrows; while those do not have appreciable deviation form spherical shape are indicated by blue arrows. (e) STEM image and (f) EDX line scans, for the elements $\mathrm{Fe}, \mathrm{Cr}, \mathrm{Al}$, and $\mathrm{Y}$, along the line marked yellow in the STEM image from the sample after compression by DPD to a strain of 1.0. The compression axis is always indicated by a double arrow. 

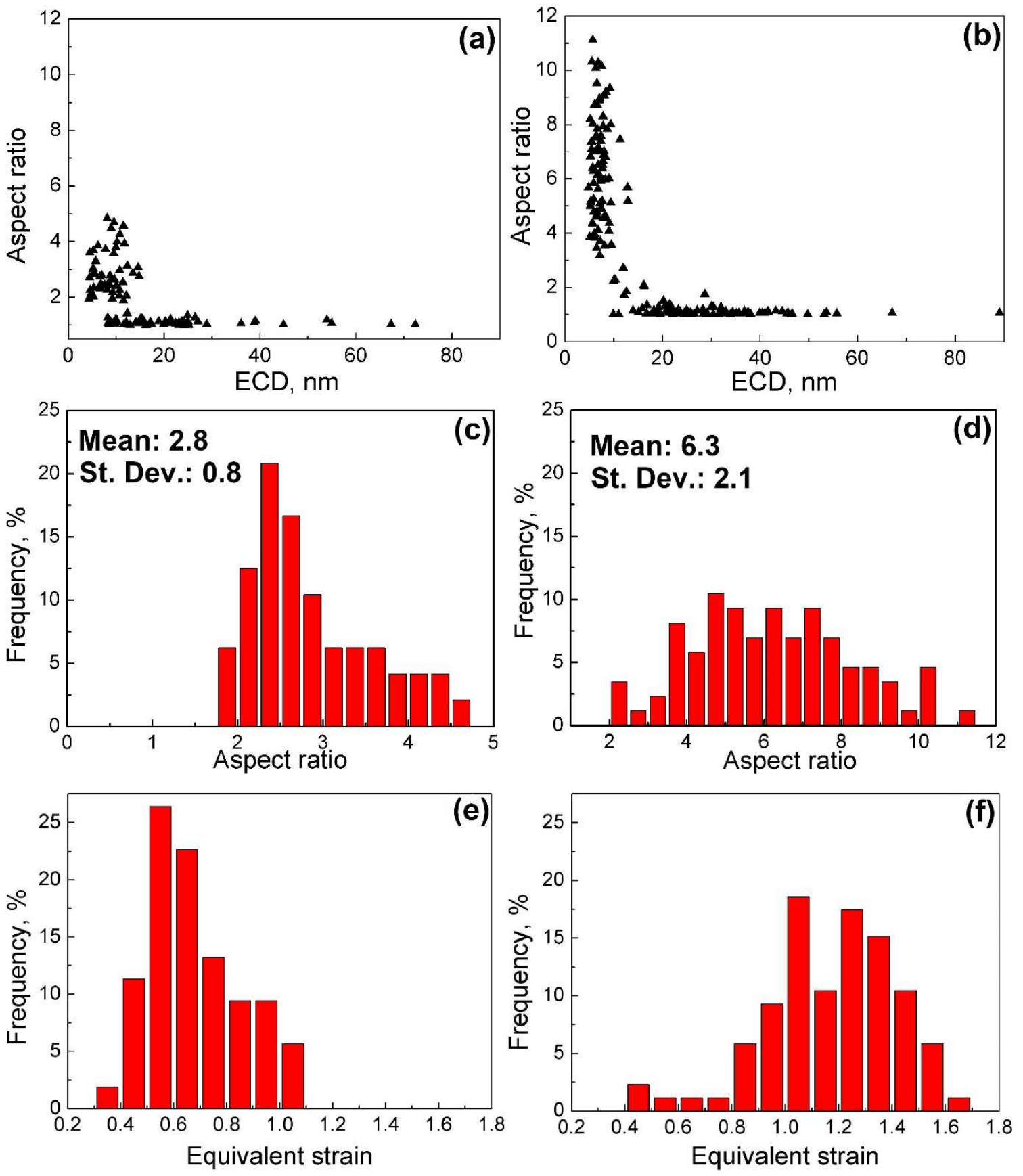

Fig. 3 Individual oxide nanoparticles in PM2000 after compression by DPD: aspect ratio versus equivalent circular diameter (ECD) after macroscopic strains of 1.0 (a) and 2.1 (b); histograms of aspect ratio of particles (for aspect ratios above 1.2) after macroscopic strains of (c) 1.0 and (d) 2.1; histogram of the equivalent plastic strain attained by the oxide nanoparticles as estimated from their aspect ratio in the longitudinal section for particles with aspect ratios above 1.2 after macroscopic strains of (e) 1.0 and (f) 2.1 . 

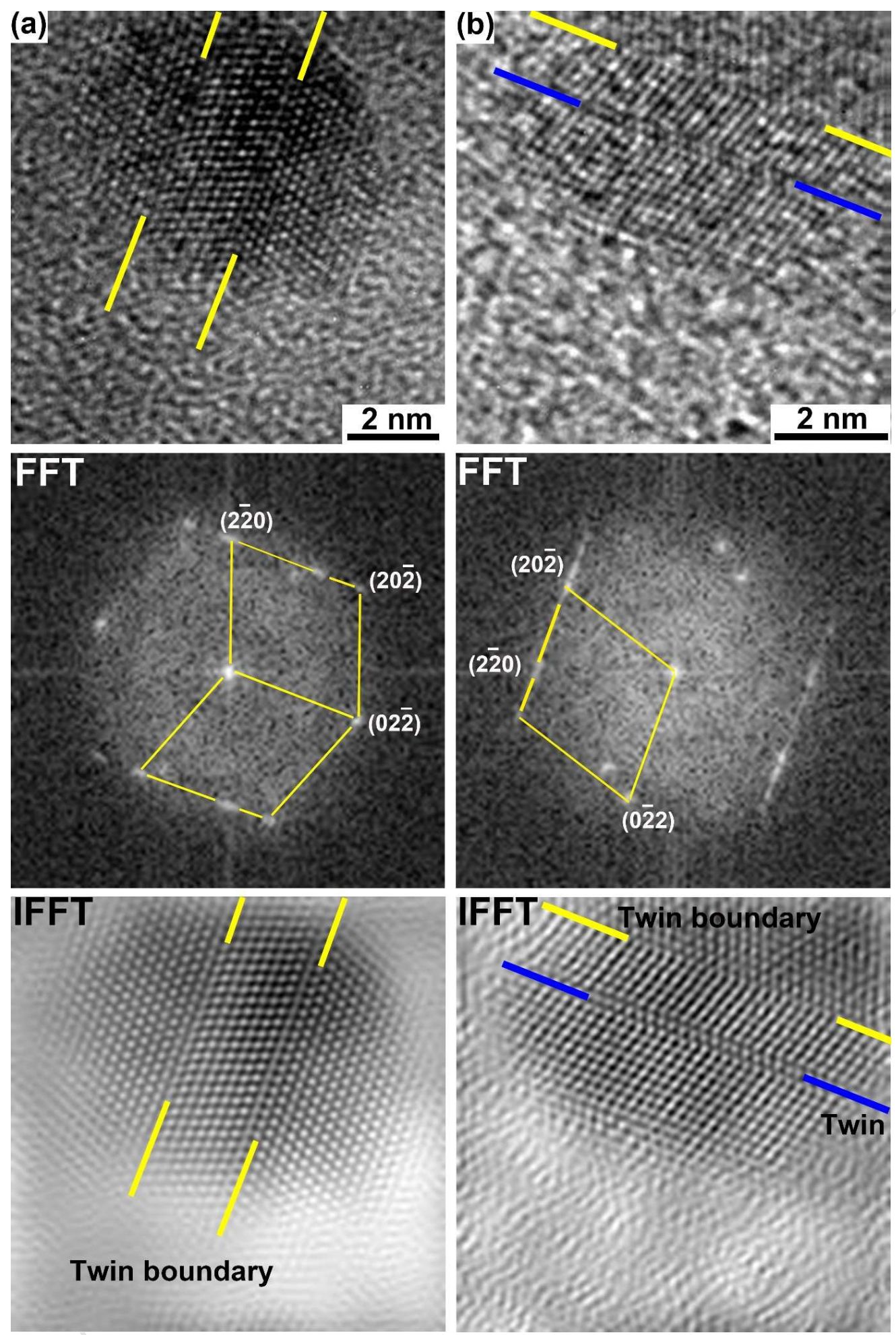

Fig. 4 HRTEM images of two oxide nanoparticles in the longitudinal section of PM2000 after compression by DPD to a strain of 0.6 (a) and (b), and their corresponding FFTs. To better visualize the structure of the oxide nanoparticles, IFFT images are constructed by filtering the background noise from the HRTEM images. Twin boundaries are indicated by yellow lines. A second defect identified as twin of minimal thickness is indicated by blue lines in (b). 


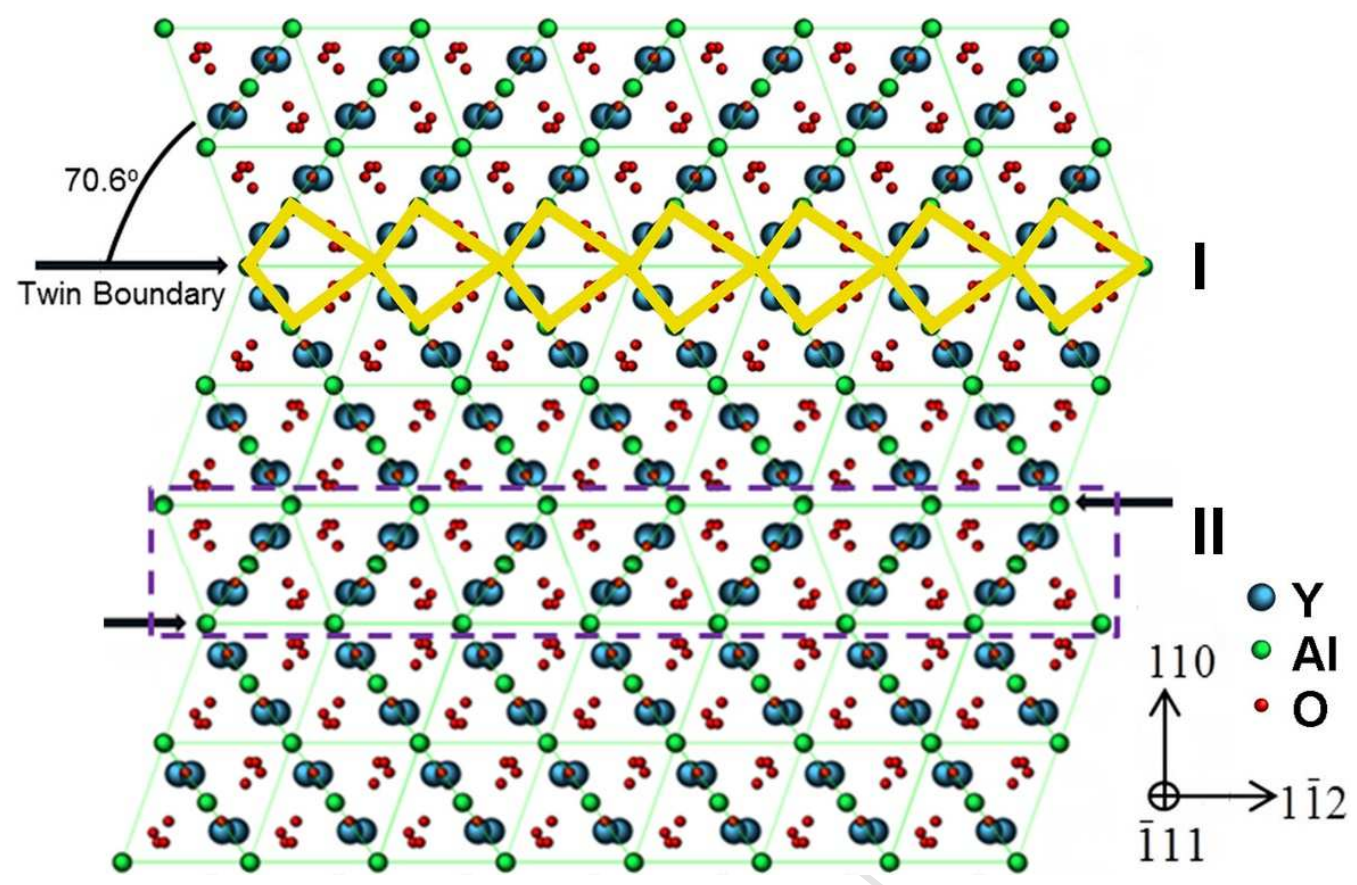

Fig. 5 Schematic diagram of (110)[112] twin structures in the crystal structure of YAP viewed along the [111] direction. Structure I indicates a twin boundary, while structure II represents a twin containing only a single layer of unit cells, i.e. a twin of minimal height. 

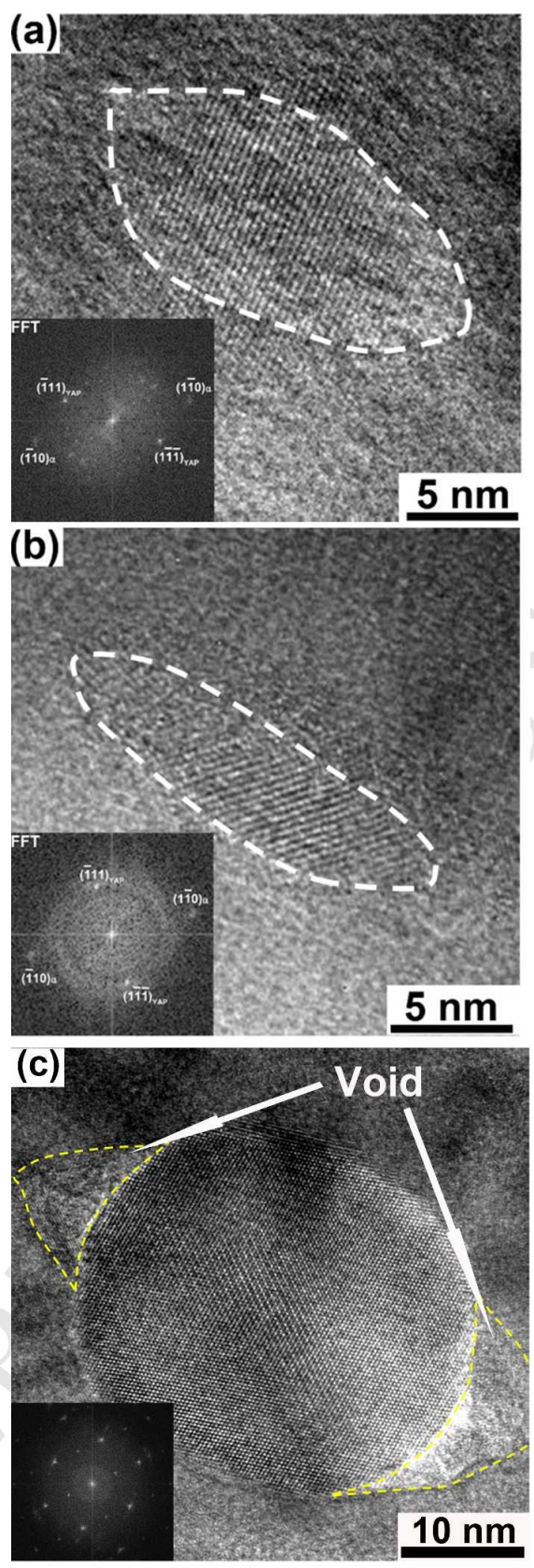

Fig. 6 HRTEM images and their corresponding FFTs of two oxide nanoparticles (outlined by dash lines) in the longitudinal section of PM2000 after compression by DPD to a macroscopic strain of 1.6, with aspect ratios of (a) 2.2 and (b) 4.4. The diffraction spots from the crystalline YAP are indexed in the inserted FFTs. (c) HRTEM image and corresponding FFT of an oxide nanoparticle in the longitudinal section of PM2000 after DPD to a macroscopic strain of 2.1. Nanovoids at the interface are outlined by yellow dashed lines. 

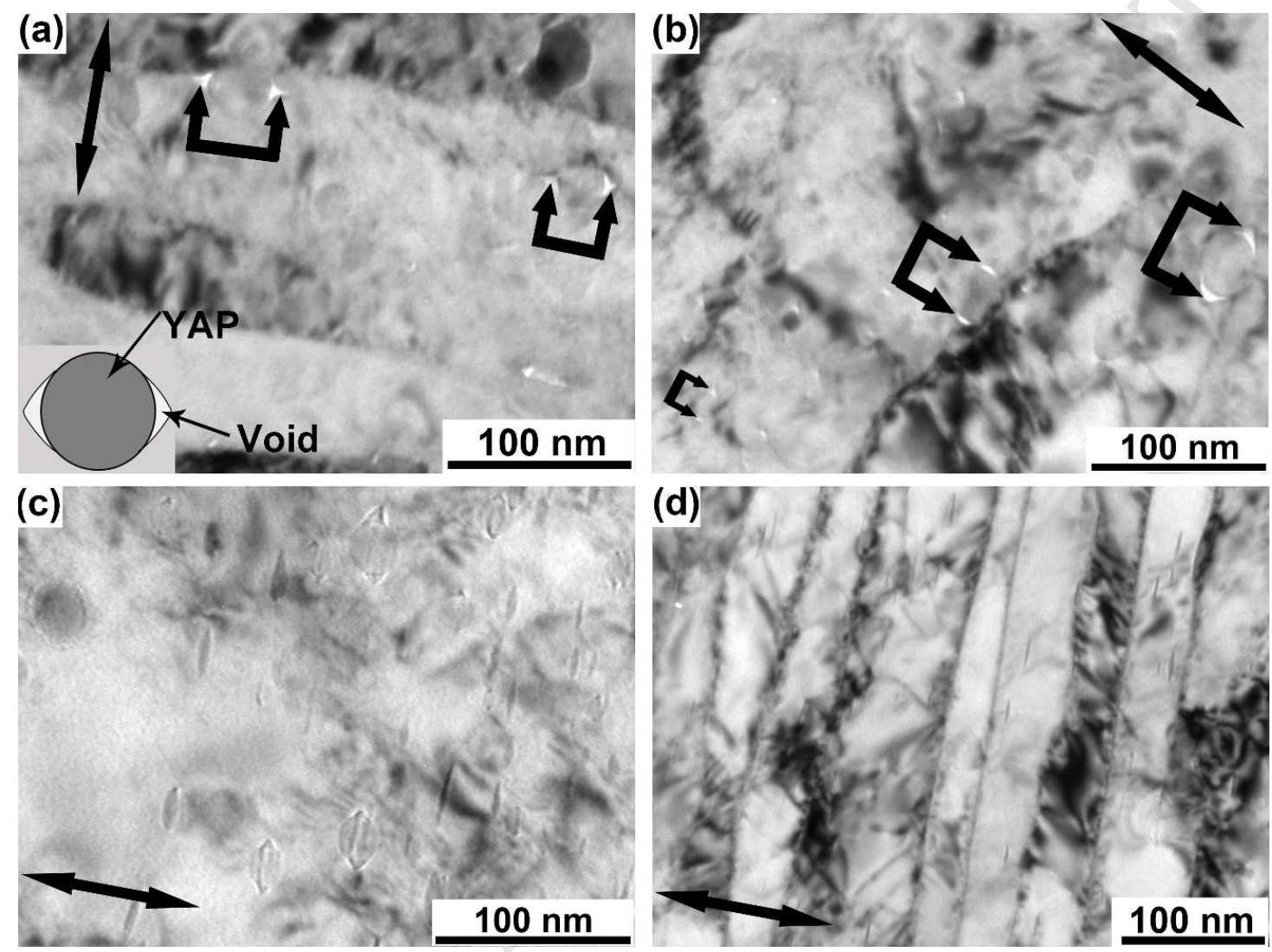

Fig. 7 TEM images of a longitudinal section of PM2000 after compression by DPD to a strain of (a) 0.6, (b) 1.0, (c) 1.6, and (d) 2.1. The black arrows in (a) and (b) point at some voids formed at the interface of YAP/Fe. A schematic diagram illustrating the morphology of the void at a YAP/Fe interface is shown in (a). The compression axis is always indicated by double arrows. 

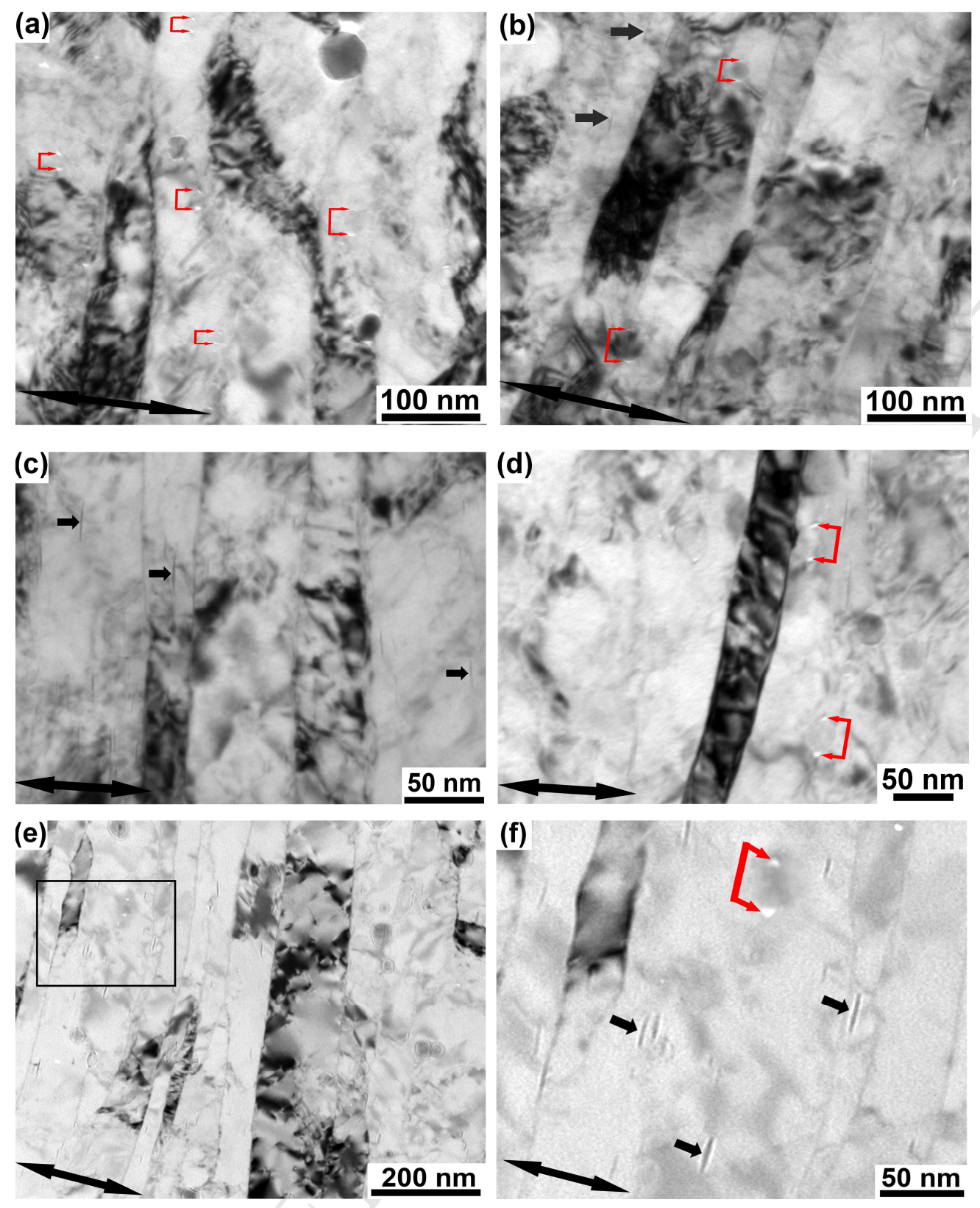

Fig. 8 TEM images showing the morphology of oxide nanoparticles from a longitudinal section: (a) and (b) PM2000 in the as-received condition after compression by DPD to a macroscopic strain of 1.0 and 2.1, respectively. (c) and (d) PM2000 after annealing at $1200{ }^{\circ} \mathrm{C}$ for $1 \mathrm{~h}$ followed by subsequent compression by DPD to a macroscopic strain of 2.1; (e) and (f) PM2000 in the as-received condition after QSC to a macorscopic strain of 2.1. Toroidal voids around nanoparticles are indicated by red arrow pairs, and highly elongated nanoparticles which are not associated with nanovoids are indicated by black arrows. The compression axis is always indicated by double black arrows. 

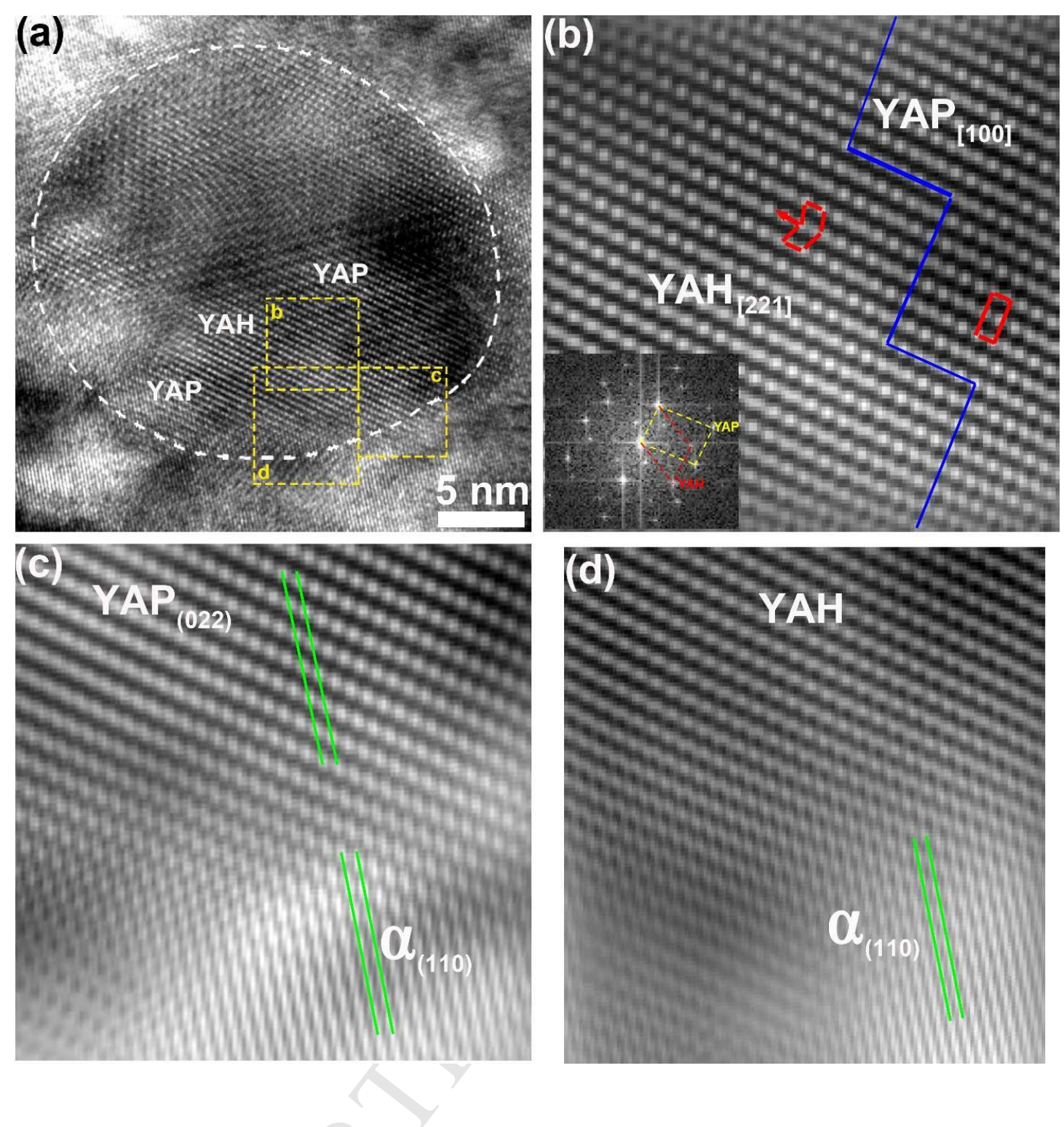

Fig. 9 (a) HRTEM image of an oxide nanoparticle (outlined by white dash line) after deformation to a strain of 2.1 , (b), (c) and (d) are the IFFT images corresponding to the enlarged yellow frames of $b, c$ and $d$ in (a). (b) boundary between [100] YAP and [221] $]_{\text {YAH }}$ (high-lighted by blue lines) in the interior of the particle; (c) interface between YAP and the ferritic steel matrix; (d) interface between transformed YAH and the matrix. 
(a)

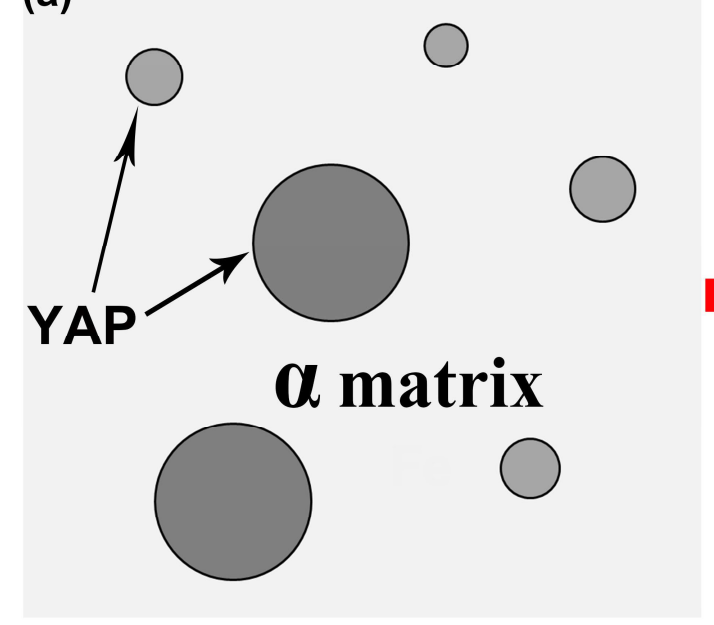

(d)

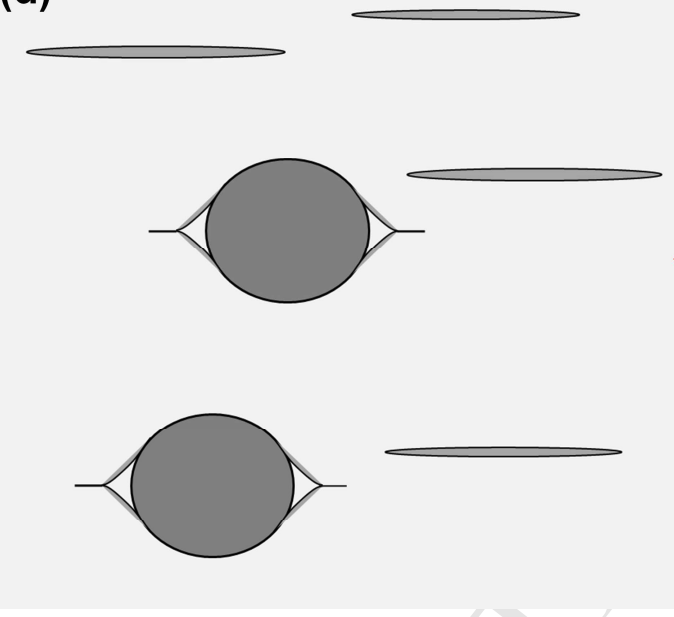

(b)

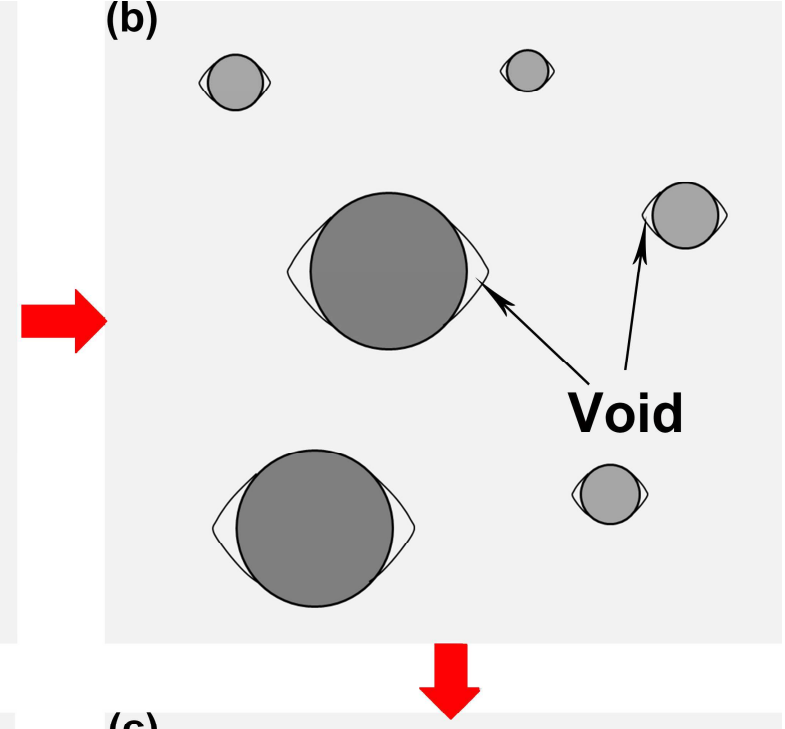

(c)

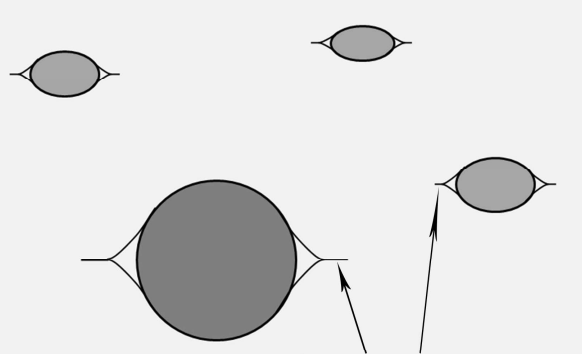

Self-welding

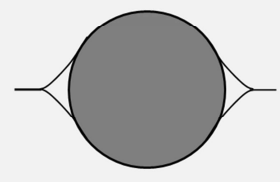

Fig. 10 Schematic diagram showing the envisaged evolution of oxide nanoparticles and the nanovoids generated at the interface. (a) YAP particles with sizes smaller than $20 \mathrm{~nm}$ and larger than $20 \mathrm{~nm}$ and the $\alpha$-Fe matrix before deformation, (b) nanovoids form at the interface around both large and small YAP particles after deformation to a low strain, (c) part of the nanovoids close due to self-welding caused by compressive stress after deformation to a medium strain, and (d) nanovoids around small particles disappear accompanied by the deformation of the particles, whilst the voids around large particle remain open. 

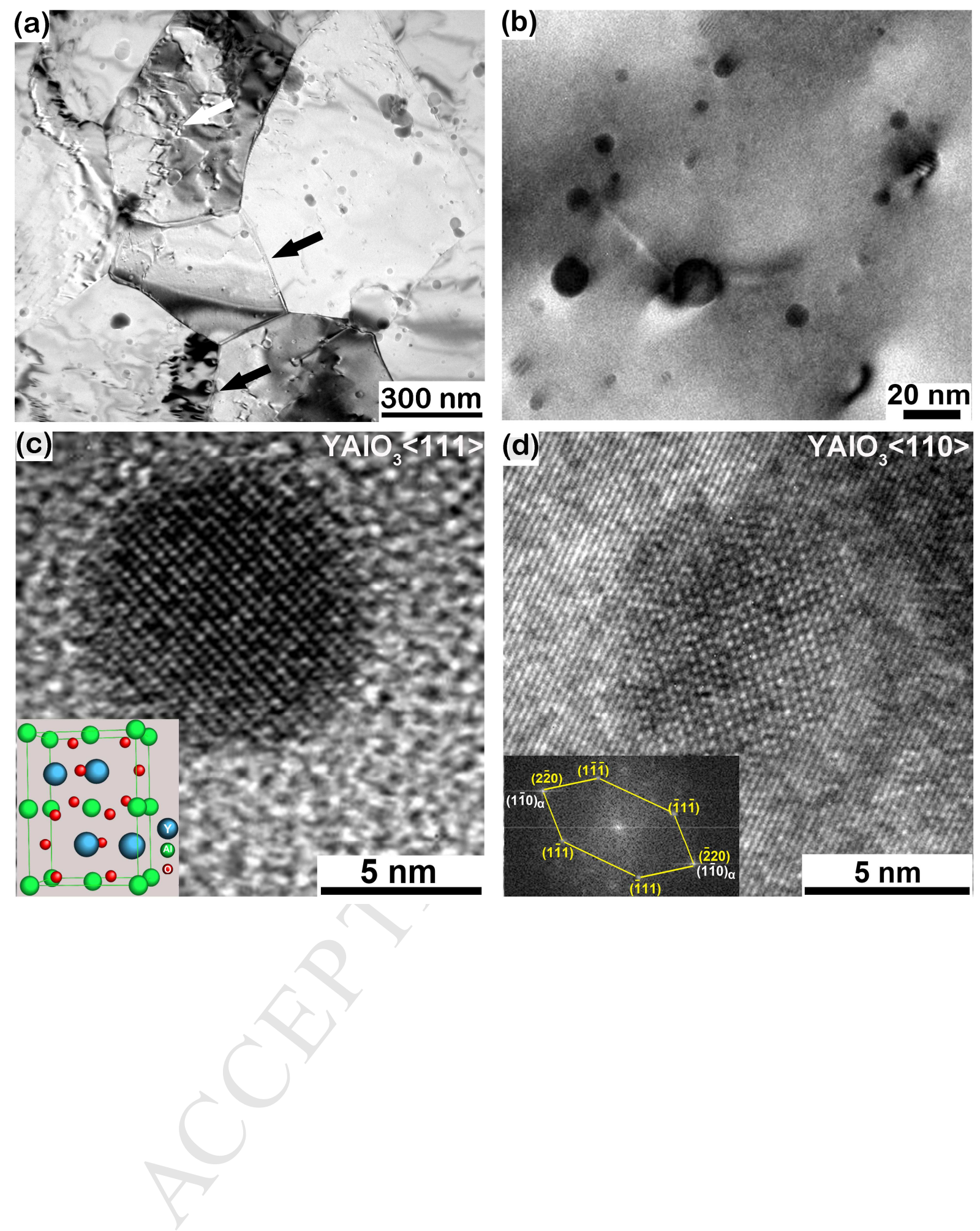

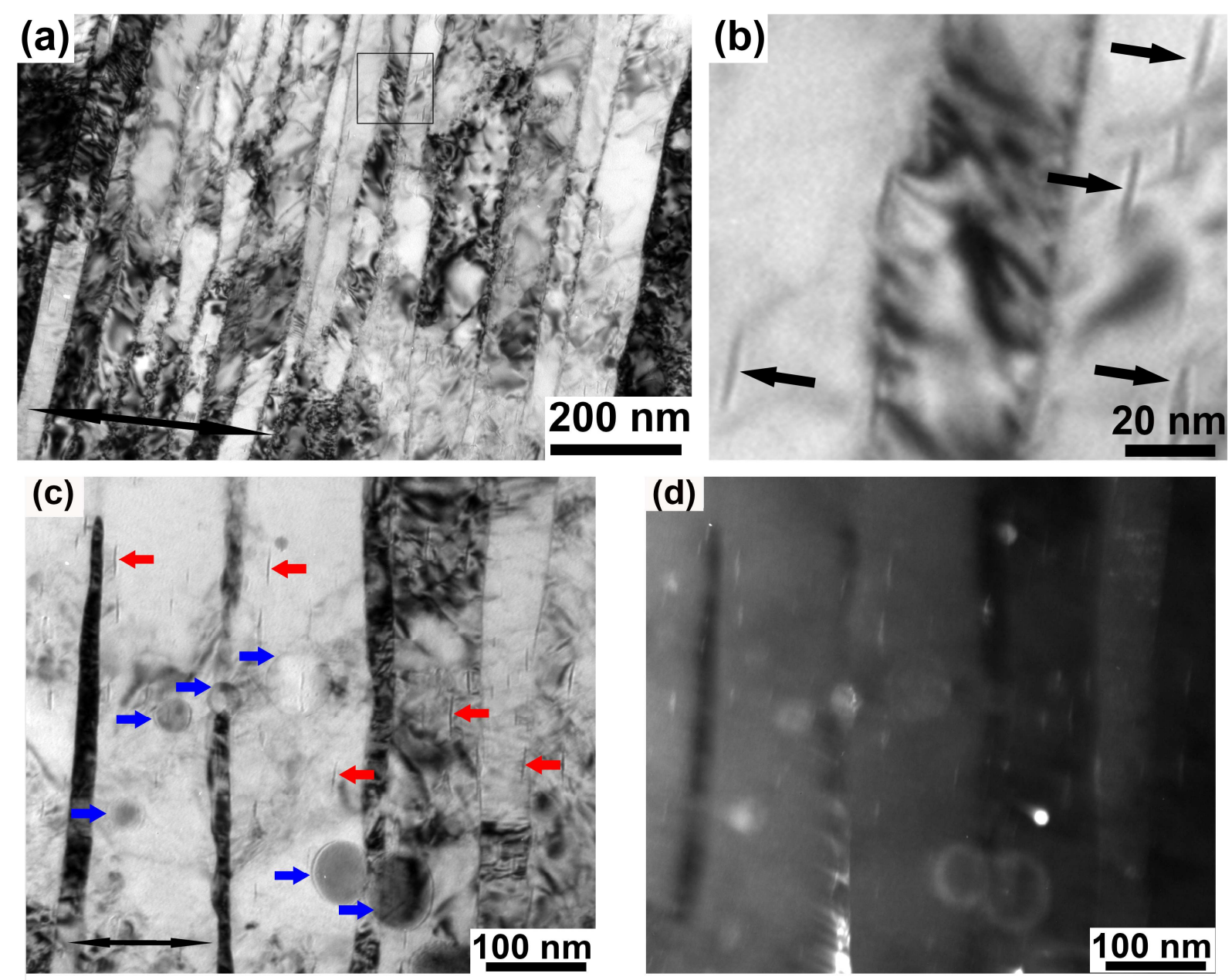

(d)

(e)

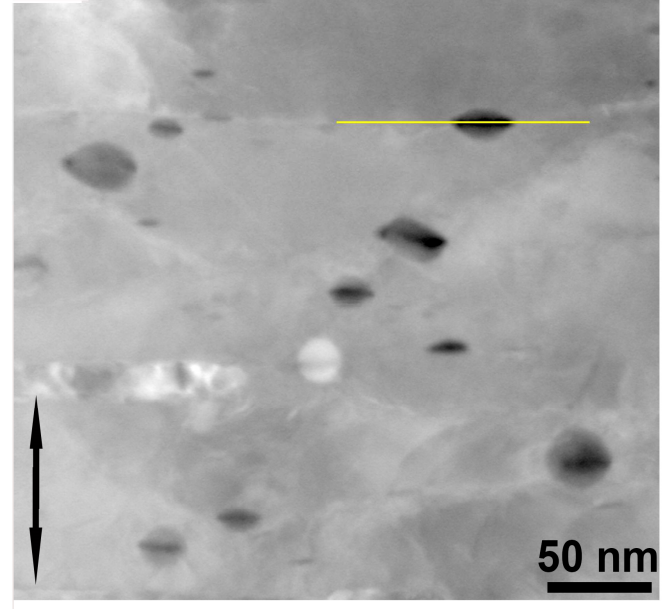

(f)
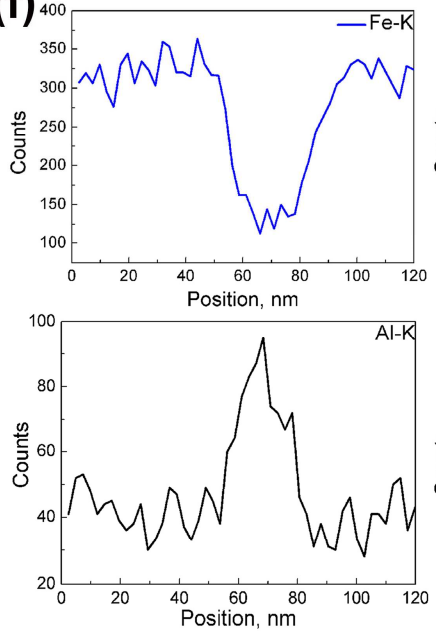
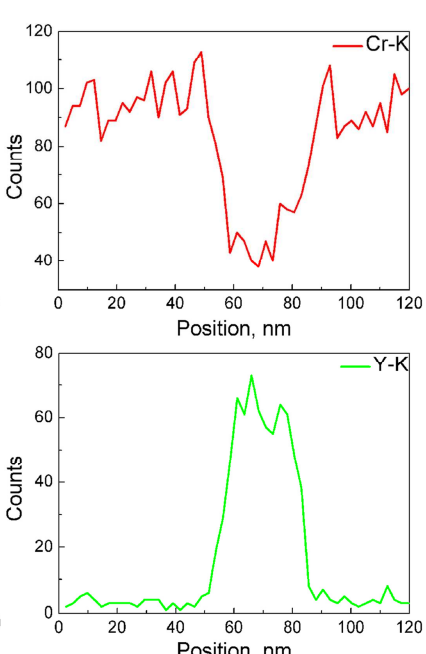

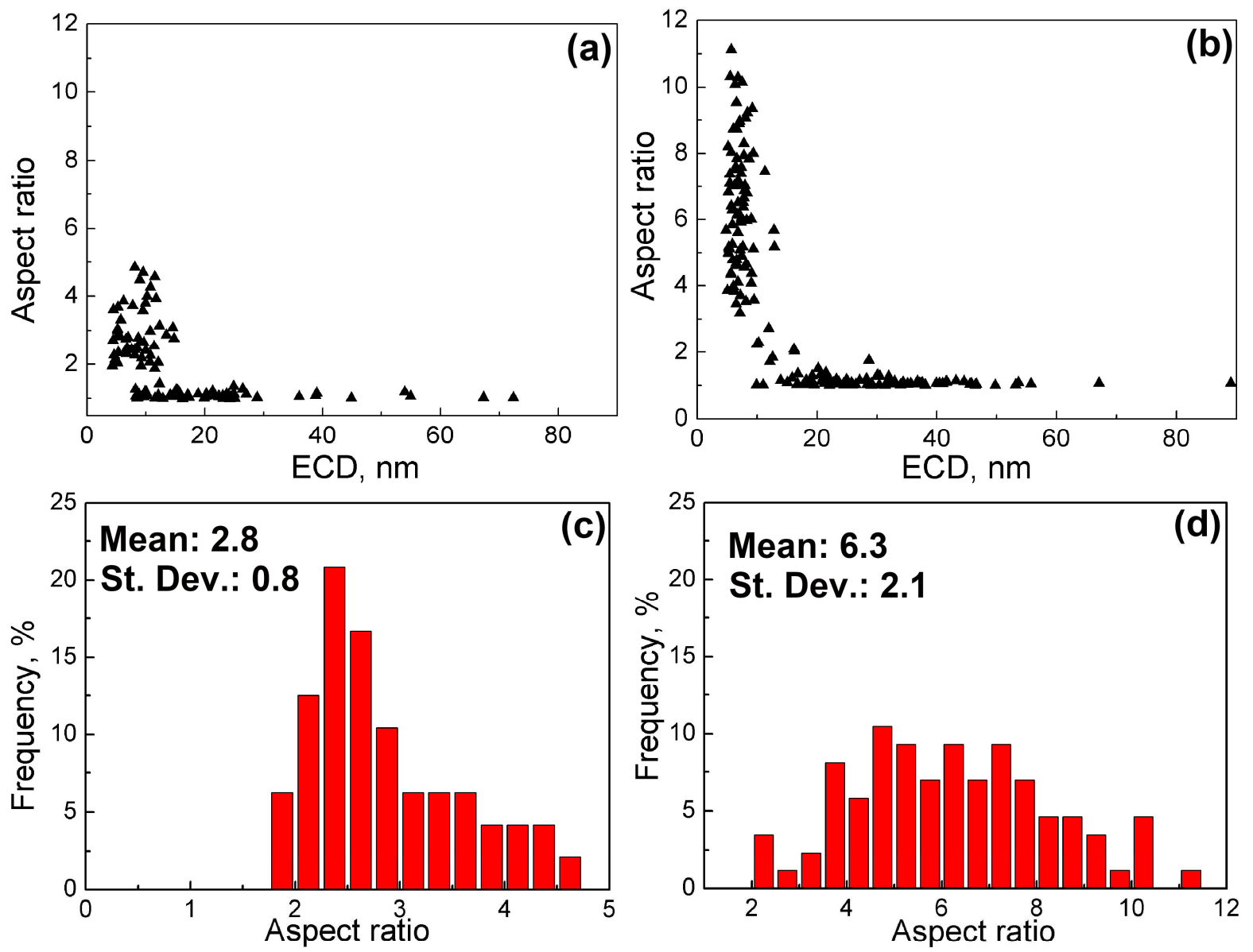

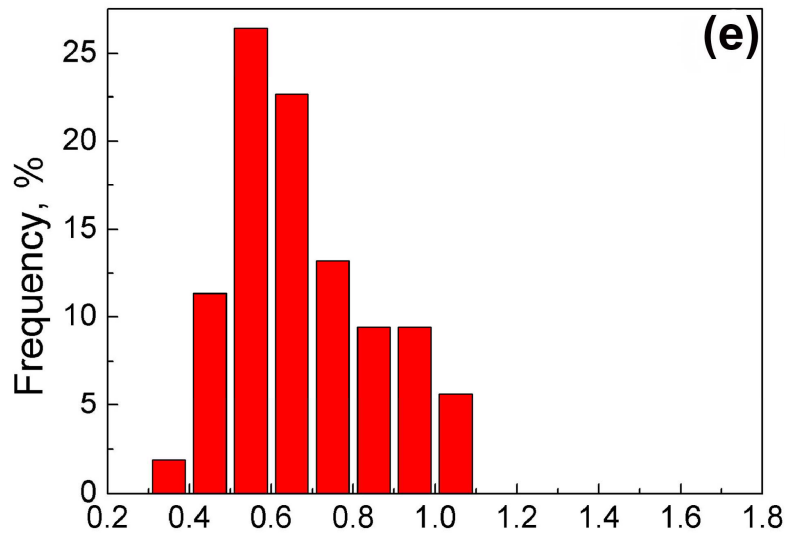

Equivalent strain

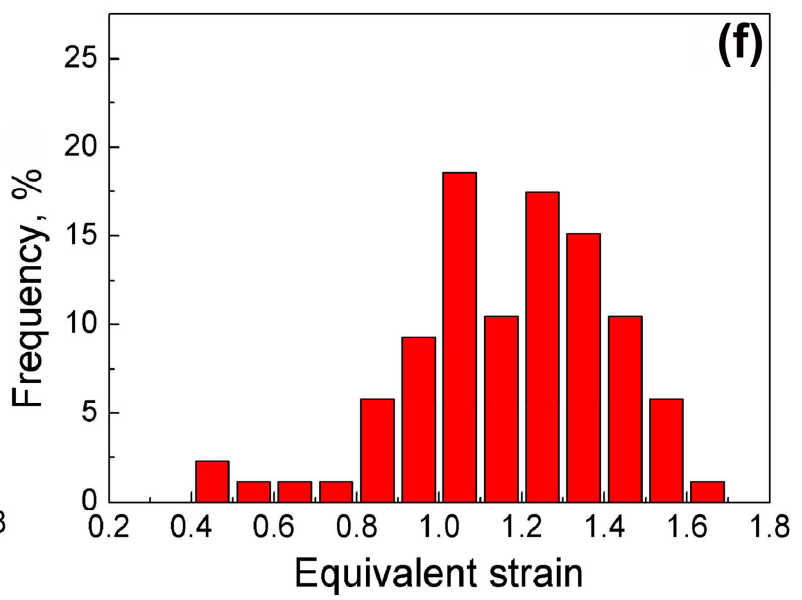


(a)
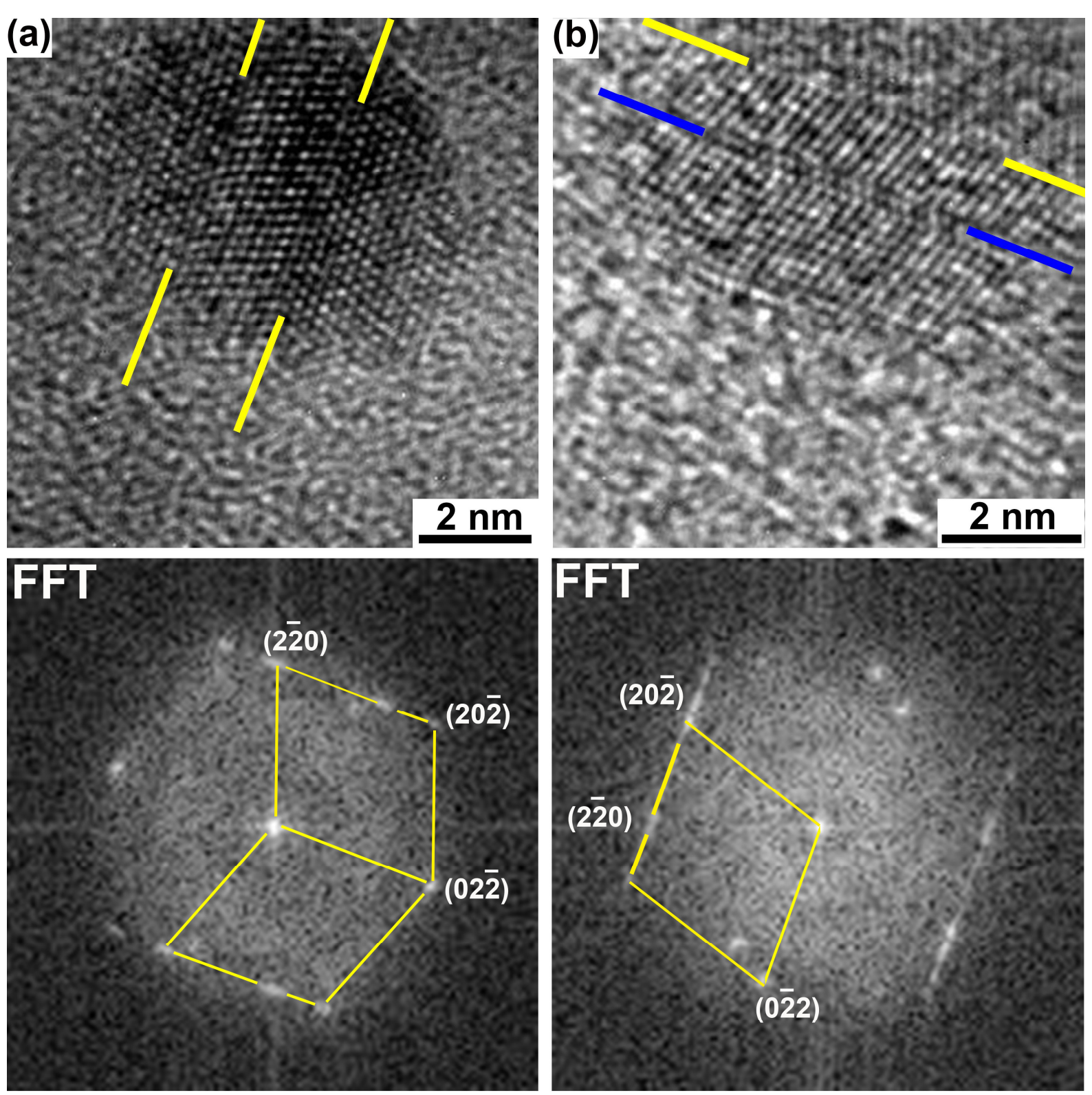

IFFT

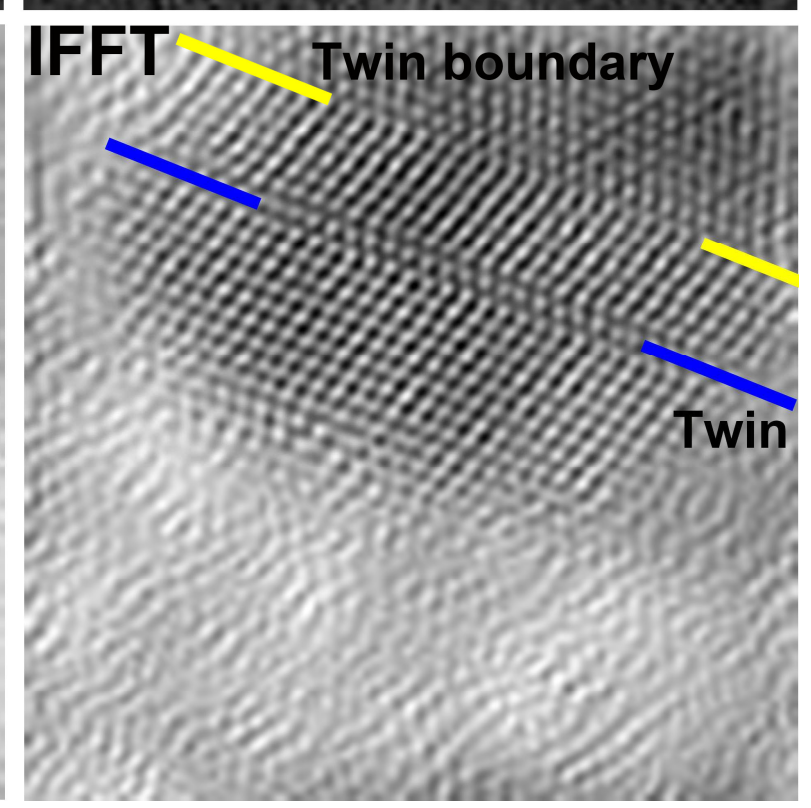

Twin boundary 


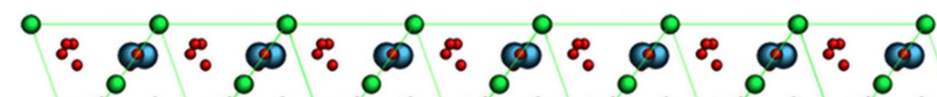

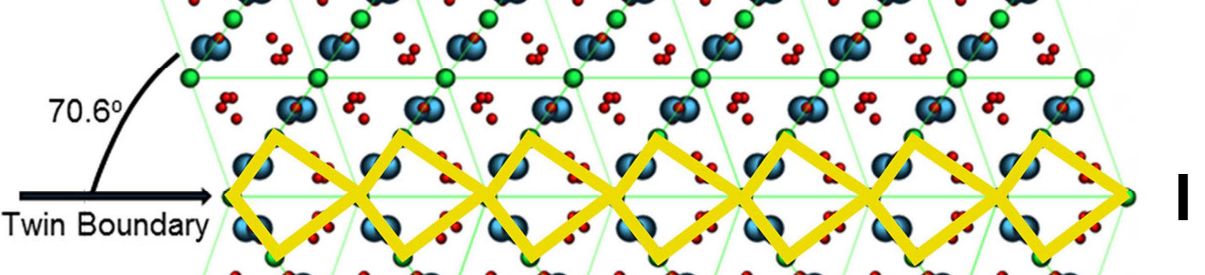

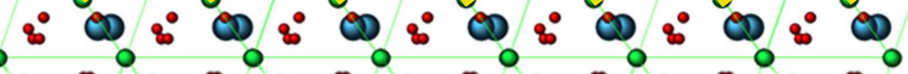

$$
\begin{aligned}
& \omega_{0}: \omega_{0}: \omega_{0}: \omega_{0}: \omega_{0}: \omega_{0}: \omega_{0}
\end{aligned}
$$

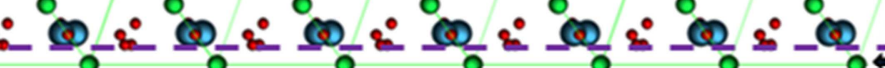

$$
\begin{aligned}
& \text { | ". }
\end{aligned}
$$

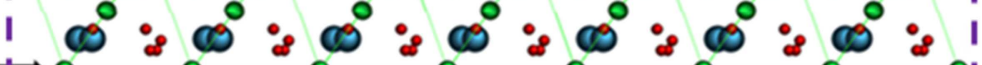

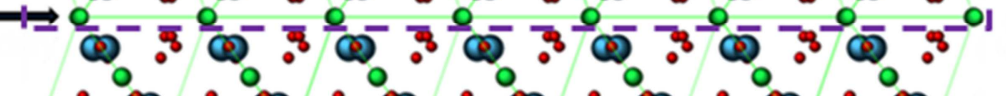

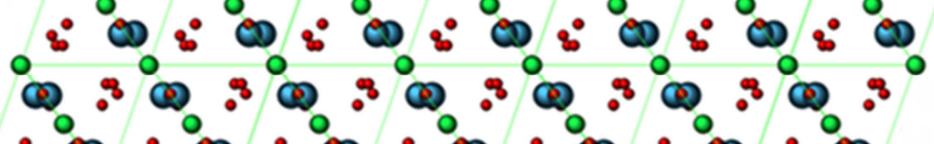

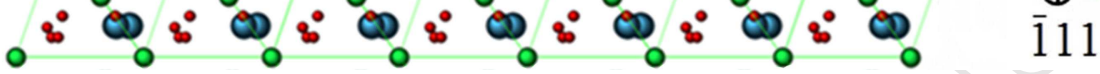


(a)
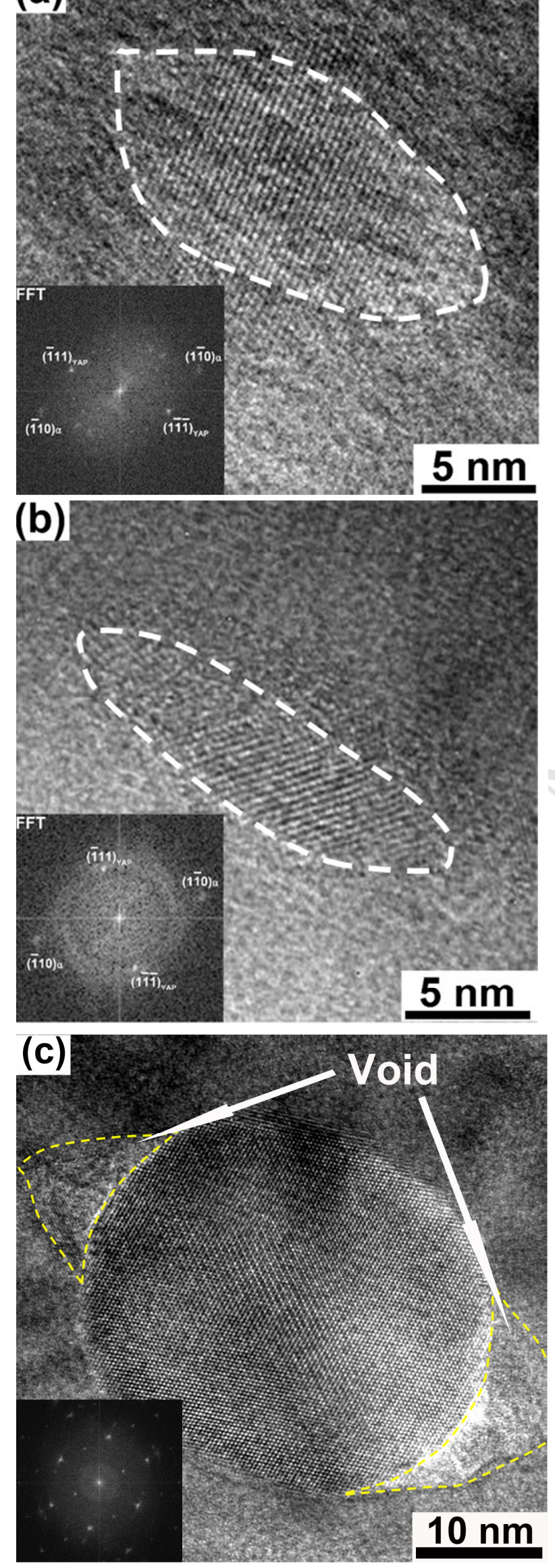

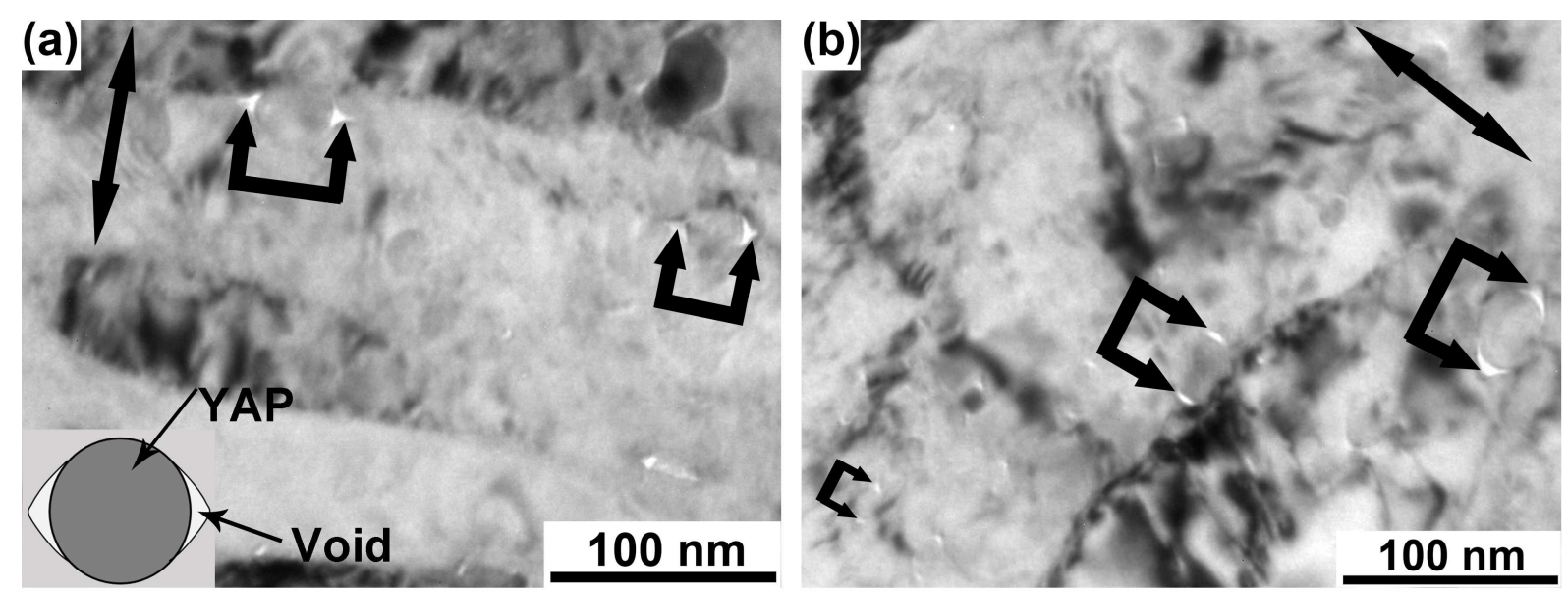

(c)

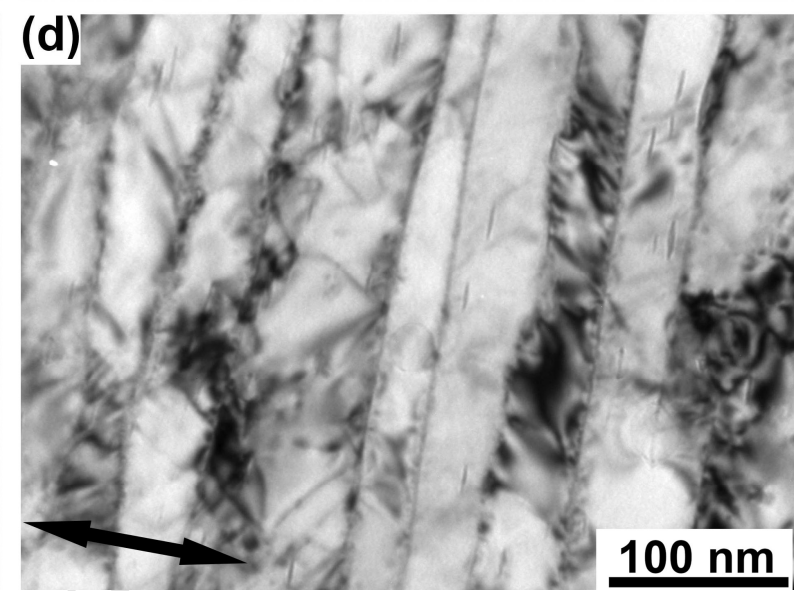




\section{ACCEPTED MANUSCRIPT}
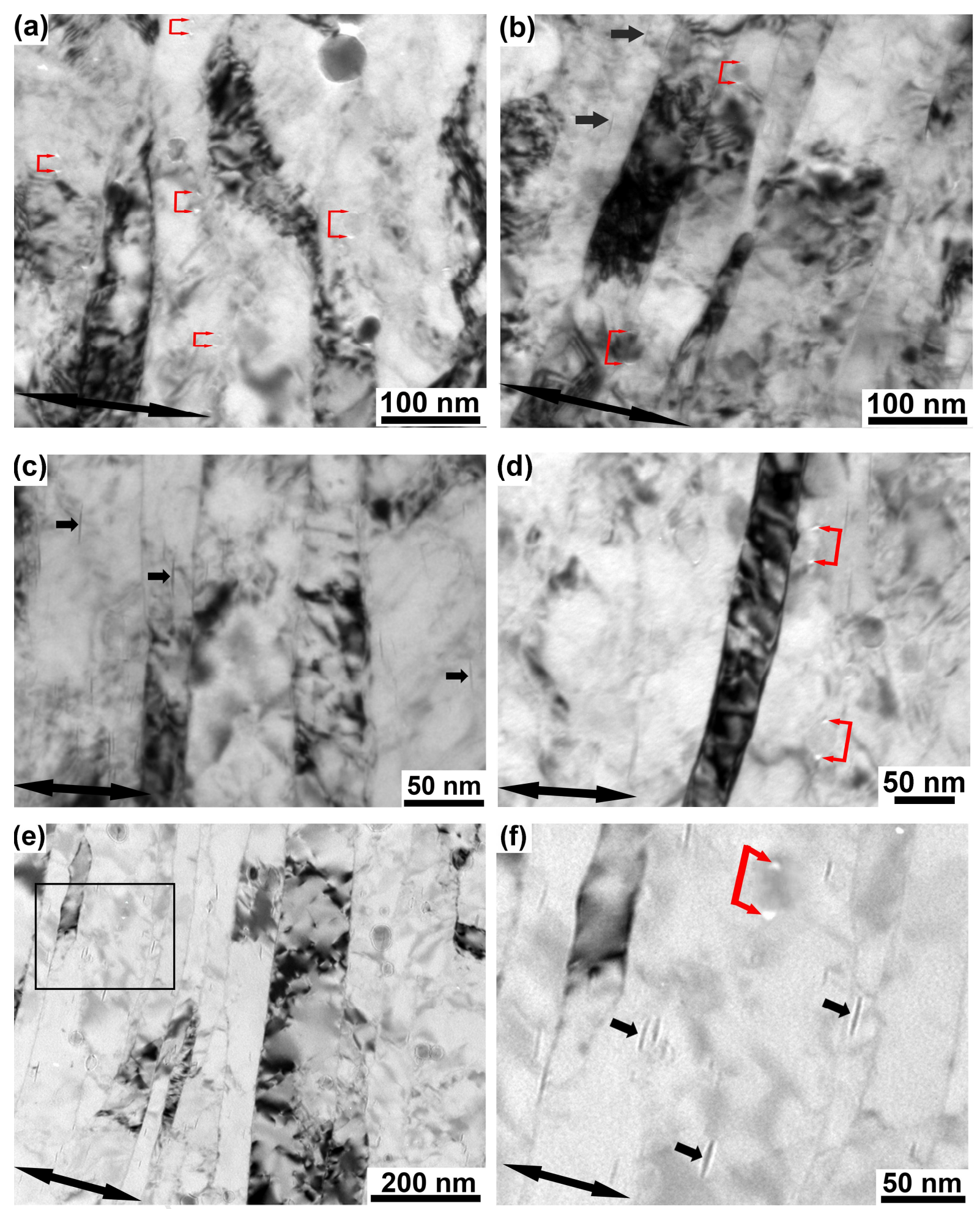

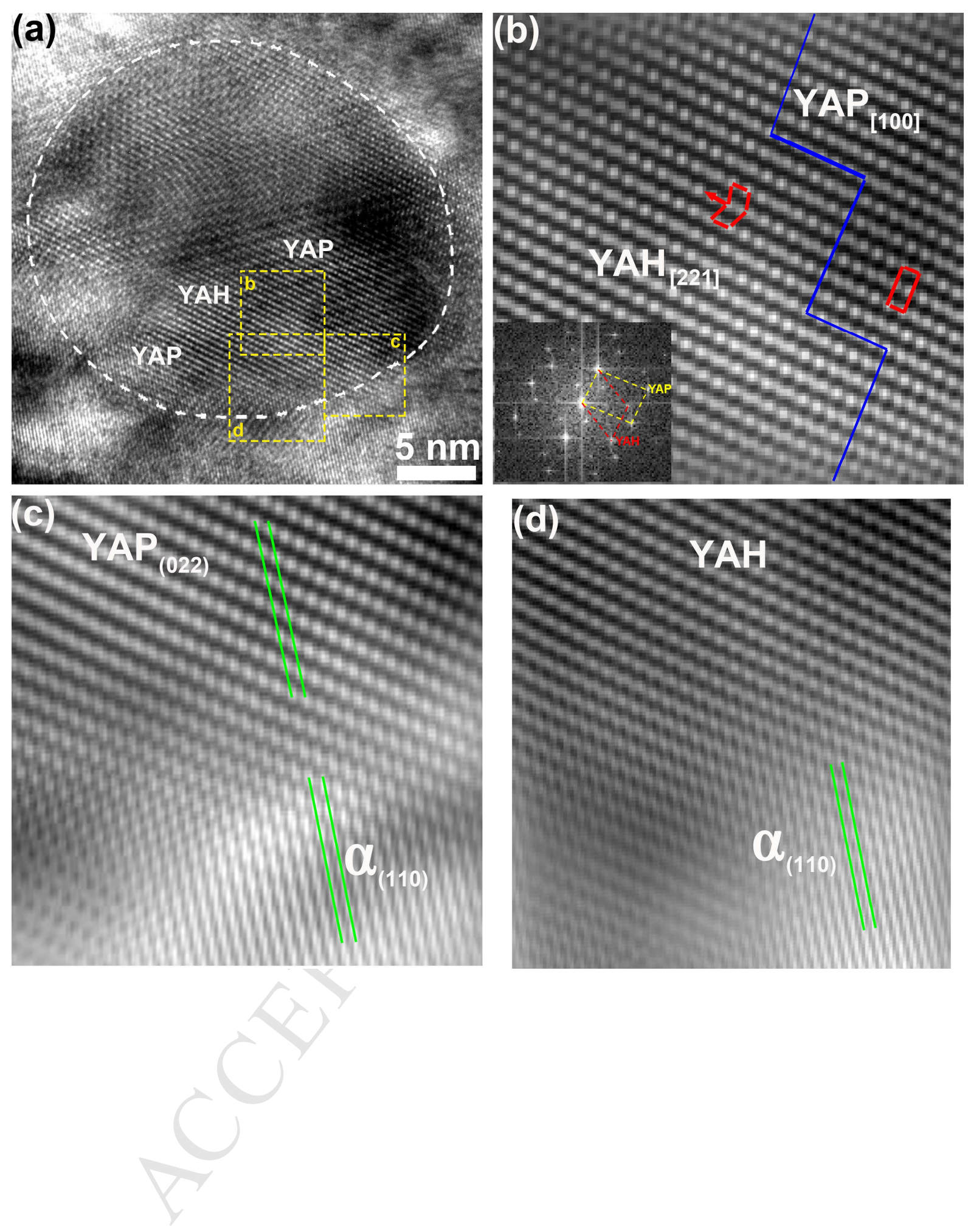
(a)

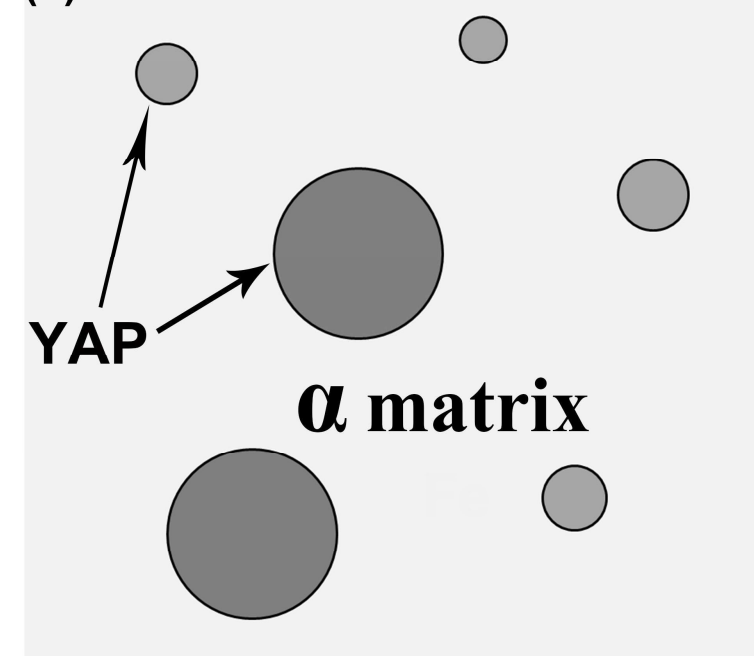

(d)
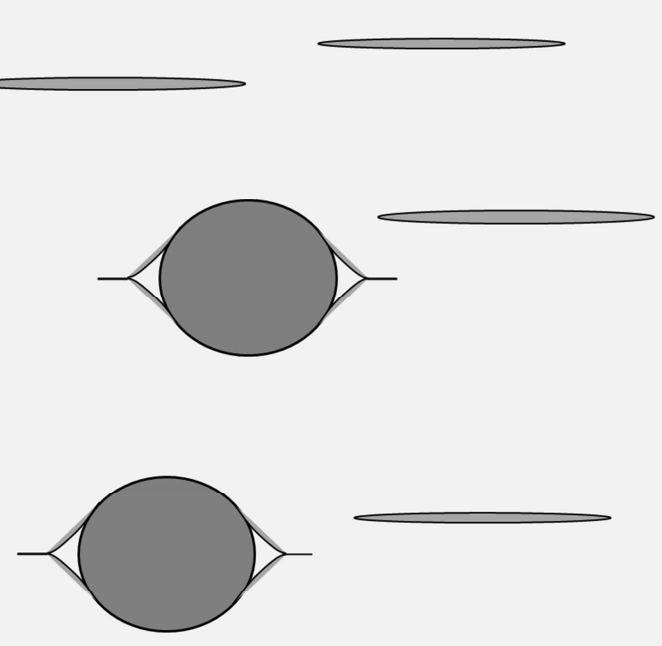

(b)

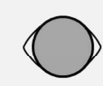

0

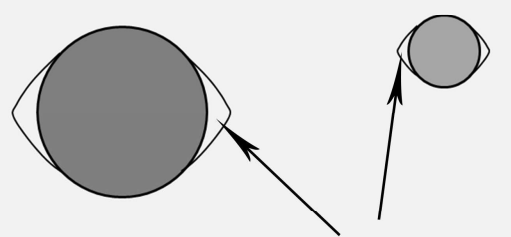

Void
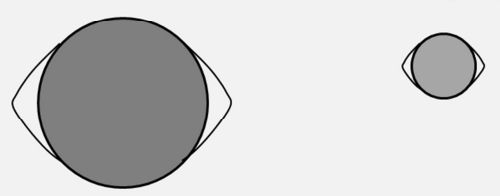

(c)

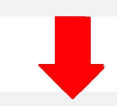

$\infty$

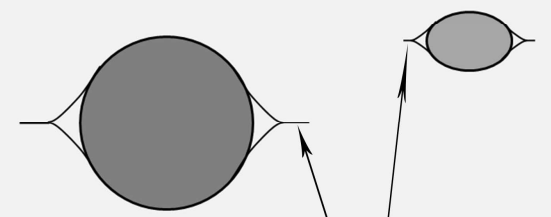

Self-welding
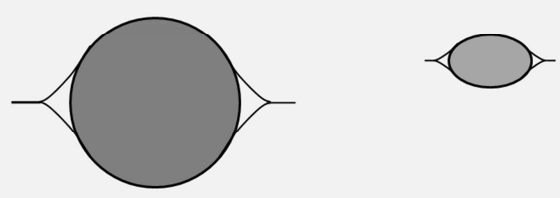